\title{
Quantitative Proteomic Analyses of a Pathogenic Strain and Its Highly Passaged Attenuated Strain of Mycoplasma hyopneumoniae
}

\author{
Sha Li iD, ${ }^{1,2}$ Liurong Fang, ${ }^{1,2}$ Wei Liu, ${ }^{3}$ Tao Song, ${ }^{1,2}$ Fuwei Zhao, ${ }^{1,2}$ Ruoxi Zhang, \\ Dang Wang, ${ }^{1,2}$ and Shaobo Xiao iD ${ }^{1,2}$ \\ ${ }^{1}$ State Key Laboratory of Agricultural Microbiology, College of Veterinary Medicine, Huazhong Agricultural University, \\ Wuhan 430070, China \\ ${ }^{2}$ The Key Laboratory of Preventive Veterinary Medicine in Hubei Province, The Cooperative Innovation Center for Sustainable \\ Pig Production, Wuhan 430070, China \\ ${ }^{3}$ Key Laboratory of Prevention and Control Agents for Animal Bacteriosis (Ministry of Agriculture), Institute of Animal Husbandry \\ and Veterinary Sciences, Hubei Academy of Agricultural Sciences, Wuhan 430070, China
}

Correspondence should be addressed to Shaobo Xiao; xiaoshaobo@mail.hzau.edu.cn

Received 17 December 2018; Revised 14 April 2019; Accepted 27 May 2019; Published 1 July 2019

Academic Editor: Clara G. de los Reyes-Gavilan

Copyright (C) 2019 Sha Li et al. This is an open access article distributed under the Creative Commons Attribution License, which permits unrestricted use, distribution, and reproduction in any medium, provided the original work is properly cited.

\begin{abstract}
Mycoplasma hyopneumoniae is the causative agent of porcine enzootic pneumonia, a chronic respiratory disease in swine resulting in enormous economic losses. To identify the components that contribute to virulence and unveil those biological processes potentially related to attenuation, we used isobaric tags for relative and absolute quantification technology (iTRAQ) to compare the protein profiles of the virulent M. hyopneumoniae strain 168 and its attenuated highly passaged strain 168L. We identified 489 proteins in total, 70 of which showing significant differences in level of expression between the two strains. Remarkably, proteins participating in inositol phosphate metabolism were significantly downregulated in the virulent strain, while some proteins involved in nucleoside metabolism were upregulated. We also mined a series of novel promising virulence-associated factors in our study compared with those in previous reports, such as some moonlighting adhesins, transporters, lipoate-protein ligase, and ribonuclease and several hypothetical proteins with conserved functional domains, deserving further research. Our survey constitutes an iTRAQ-based comparative proteomic analysis of a virulent $M$. hyopneumoniae strain and its attenuated strain originating from a single parent with a well-characterized genetic background and lays the groundwork for future work to mine for potential virulence factors and identify candidate vaccine proteins.
\end{abstract}

\section{Introduction}

M. hyopneumoniae is the causative agent of porcine enzootic pneumonia, which is a worldwide epidemic that can cause enormous economic losses as a result of retarded growth in pigs and the cost of disease control [1]. Despite its low direct mortality, M. hyopneumoniae increases the host's susceptibility to secondary respiratory infections by damaging cilia and epithelial cell, resulting in aggravated lung lesions and fatal respiratory diseases [2]. To date, the determination of the potential molecular mechanisms of the pathogenicity of $M$. hyopneumoniae has been hampered by the fastidious growth requirements of this organism and the lack of tools for its genetic manipulation.

Comparative genomic analyses have been performed to reveal the genetic basis of virulence attenuation of $M$. hyopneumoniae and to predict potential virulence factors [35]. However, in the case of M. hyopneumoniae, the different strains share highly similar genome structures and gene orders, and few differences have been detected among them at the genomic level. Thus, we decided to turn our attention to the variations in expression levels of the predicted virulence factors. 
Previous studies have described the transcriptome changes under different growth conditions [6-9] and with changes in gene regulation among different mycoplasma species [10]. No transcriptomic studies comparing virulent and avirulent $M$. hyopneumoniae strains have been published. The comparative proteomic reports of pathogenic and nonpathogenic strains based on two-dimensional gel electrophoresis have revealed a few differentially expressed proteins [11-13]. However, gel-based proteomic methods are usually hindered by their low-throughput and the difficulty of direct quantitative comparison between samples. Recently, Paes et al. adopted cell fractioning technology coupled with mass spectrometry, providing much more potential virulence factor/vaccine candidates than conventional ones through comparative whole cell proteome profiles analysis of two $M$. hyopneumoniae strains and M. flocculare [14].

In this study, we undertook a large-scale proteomic comparison between the virulent $M$. hyopneumoniae strain 168 and its highly passaged attenuated vaccine strain $168 \mathrm{~L}$ and identified differentially displayed proteins using the nongel-based isobaric tags for relative and absolute quantification (iTRAQ) approach. This survey supplied a comprehensive iTRAQ-based comparative proteomic analysis of a pathogenic and a nonpathogenic M. hyopneumoniae strain, both originating from one parent strain with a wellcharacterized genetic background. This approach eliminated the effects caused by differences at the genome level, and it demonstrated some novel promising virulence-related proteins in these strains compared with previous researches.

\section{Materials and Methods}

2.1. Ethics Statement. The animal experiments in this study were approved by The Scientific Ethic Committee of Huazhong Agricultural University, Wuhan, China (Approval Number: HZAURAB-2017-008) and conducted in accordance with the Hubei Regulations for the Administration of Affairs Concerning Experimental Animals.

2.2. Mycoplasma Strains and Their Cultivation. M. hyopneumoniae strains 168 and 168L were acquired from the Jiangsu Academy of Agricultural Sciences (Nanjing, China). M. hyopneumoniae strain 168 is a pathogenic strain isolated in China in 1974, leading typical mycoplasmal pneumonia of swine $[5,15]$. The stable attenuated strain 168L was obtained after 380 continuous serial passages in KM2 cell-free medium (a modified Friis medium) and has been developed into a commercially available vaccine against $M$. hyopneumoniae in China $[5,16]$. Cultures were maintained in KM2 cell-free medium at $37^{\circ} \mathrm{C}$. For the proteomic study, $1.5 \mathrm{~L}$ cultures of strains 168 and $168 \mathrm{~L}$ were grown to late-log phase as described by Calus [17]. Three replicate samples of each culture were harvested by centrifugation at $1,2000 \times \mathrm{g}$ for 30 minutes at $4^{\circ} \mathrm{C}$ and washed three times with ice-cold PBS.

2.3. Protein Extraction, Digestion, and Labeling with iTRAQ Reagents. Bacterial cells were resuspended in lysis buffer (7 M urea, $2 \mathrm{M}$ thiourea, 4\% CHAPS, $40 \mathrm{mM}$ Tris- $\mathrm{HCl}$,
$\mathrm{pH}$ 8.5) containing $1 \mathrm{mM}$ PMSF, $2 \mathrm{mM}$ EDTA, and 10 mM DTT. The samples were then sonicated for further protein solubilization. After centrifugation $\left(25,000 \times \mathrm{g}, 4^{\circ} \mathrm{C}\right.$, $20 \mathrm{~min}$ ), the protein concentration of the supernatants was determined using the Bradford assay. Each sample $(100 \mu \mathrm{g})$ was digested with trypsin (Promega, Madison, WI, USA) at $37^{\circ} \mathrm{C}$ for $12 \mathrm{~h}$. The three lysate replicates of M. hyopneumoniae strain 168 were labeled with iTRAQ reagents 113, 114, and 115, and of strain 168L with iTRAQ reagents 116, 117, and 119.

2.4. SCX Chromatography. iTRAQ-labeled mixed peptides were fractionated by SCX chromatography using a $20 \mathrm{AB}$ HPLC system (Shimadzu, Kyoto, Japan). Peptide mixture was reconstituted in buffer $\mathrm{A}\left(25 \mathrm{mM} \mathrm{NaH}_{2} \mathrm{PO}_{4}\right.$ in $25 \%$ acetonitrile, $\mathrm{pH} 2.7)$ and loaded onto an UltremexSCX column (4.6 $\times 250 \mathrm{~mm}$ ). The loaded peptides were eluted at a flow rate of $1 \mathrm{ml} / \mathrm{min}$ with $5 \%$ buffer $\mathrm{B}\left(25 \mathrm{mM} \mathrm{NaH}_{2} \mathrm{PO}_{4}, 1 \mathrm{M} \mathrm{KCl}\right.$ in $25 \%$ acetonitrile, $\mathrm{pH} 2.7$ ) for $7 \mathrm{~min}$, a linear gradient of $5-60 \%$ and $60-100 \%$ buffer $\mathrm{B}$ for $20 \mathrm{~min}$ and $2 \mathrm{~min}$, respectively, and $100 \%$ buffer $\mathrm{B}$ for $1 \mathrm{~min}$ and then $5 \%$ buffer $\mathrm{B}$ for 10 min. The chromatograms were recorded at $214 \mathrm{~nm}$. In total, 20 fractions were collected, desalted with a StrataX desalting column, and dried using vacuum centrifugation.

2.5. LC-MS/MS Analysis. The lyophilized fractions were resuspended in buffer $\mathrm{A}$ ( $5 \%$ acetonitrile, $0.1 \%$ formic acid) and loaded on a Symmetry C18 trapping column (5 $\mu \mathrm{m}$ particles, $180 \mu \mathrm{m}$ inner diameter $\times 20 \mathrm{~mm}$; Waters) for online trapping and desalting. Then the peptides were eluted from the trapping column over a BEH $130 \mathrm{C} 18$ column $(1.7 \mu \mathrm{m}$ particles, $100 \mu \mathrm{m}$ inner diameter $\times 100 \mathrm{~mm}$ ) with a gradient buffer B (95\% acetonitrile, $0.1 \%$ formic acid) at $300 \mathrm{~nL} / \mathrm{min}$ (5-35\% B, 35 min; 35-60\% B, 5 min; 80\% B, 2 min; 80-5\% B, 1 $\min ; 5 \% \mathrm{~B}, 10 \mathrm{~min})$.

MS/MS was operated with a Triple TOF 5600 mass spectrometer (AB Sciex, Concord, ON). Data were acquired using a nanospray voltage of $2.5 \mathrm{kV}$, an interface heater temperature of $150^{\circ} \mathrm{C}$, curtain gas at $30 \mathrm{psi}$, and nebulizer gas at 15 psi. Survey scans were acquired in $250 \mathrm{~ms}$ and as many as 30 product ion scans were collected if exceeding the threshold of 120 counts per second (cps) with +2 to +5 charge states. Total cycle time was fixed at $3.3 \mathrm{~s}$. Dynamic exclusion was set for $1 / 2$ of peak width (18 s) and the fragmentation energy was set to $35 \pm 5 \mathrm{eV}$.

2.6. Protein Identification and Quantification. Tandem mass spectra were extracted by AB SCIEX MS Data Converter version 1.3. All MS/MS data were analyzed using the Mascot search algorithm (Matrix Science, London, UK; version b2.5.1) against the NCBI M. hyopneumoniae $168 \& 168 \mathrm{~L}$ database (201607, 3408 entries) with trypsin as the digestion enzyme. For protein identification, Mascot was searched with a parent ion tolerance of $15 \mathrm{ppm}$ and a fragment ion mass tolerance of $0.050 \mathrm{Da}$. Carbamidomethyl of cysteine and iTRAQ8plex of lysine and the n-terminus were specified in Mascot as fixed modifications, while oxidation of methionine and iTRAQ8plex of tyrosine were allowed as variable modifications. 
MS/MS-based peptide and protein identifications were validated using Scaffold (version Scaffold_4.6.1, Proteome Software Inc., Portland, OR). Peptide identifications were accepted if they could be established with less than $1 \%$ false discovery rate (FDR) by the Scaffold Local FDR algorithm, and each identified protein involved at least one unique peptide.

Scaffold Q+ (version Scaffold_4.6.1, Proteome Software Inc., Portland, OR) was used to quantitate the isobaric tag peptide and protein identifications. Normalization was performed iteratively (across samples and spectra) on intensities. Medians were used for averaging. Spectra data were logtransformed, pruned of those matched to multiple proteins, and weighted by an adaptive intensity weighting algorithm. A protein was considered to be differentially displayed if it contained at least two unique peptides with a minimum fold change of 0.585 on the $\log 2$ scale, and Mann-Whitney Test with an unadjusted significance level $\mathrm{p}<0.05$ corrected by the Benjamini-Hochberg method.

2.7. Bioinformatic Analysis of Proteins. Gene Ontology (GO) analysis was performed to map all of the identified proteins to GO terms in database (http://www.geneontology.org/). The metabolic pathway of identified proteins was performed using the Kyoto Encyclopedia of Genes and Genomes (KEGG) database (https://www.genome.jp/kegg/). The significantly enriched GO terms or pathways of differentially expressed proteins in the background of the identified proteins were determined by a hypergeometric test $(\mathrm{p}<0.05)$.

The physical and chemical parameters of the given proteins were computed via ProtParam tool (https:// web.expasy.org/protparam/) [18]. Lipoprotein signal peptides were predicted by LIPO (http://services.cbu.uibno/.tools/ lipo) [19] and LipoP 1.0 Server (http://www.cbs.dtu.dk/ services/LipoP/) [20]. Subcellular location of proteins was predicted by using PSORTb version 3.0.2 (https:// www.psort.org/psortb/index.html) [21] and CELLO v.2.5 (http://cello.life.nctu.edu.tw/) [22]. TMHMM v2.0 (http:// www.cbs.dtu.dk/services/TMHMM-2.0/) and SignalP v.4.1 (http://www.cbs.dtu.dk/services/SignalP/) were used for predicting transmembrane helices and the presence and location of signal cleavage sites, respectively [23, 24]. SecretomeP 2.0 server (http://www.cbs.dtu.dk/services/ SecretomeP/) was used to identify nonclassical protein secretion, i.e., not signal peptide triggered protein secretion [25]. Uncharacterized/hypothetical proteins were subjected to BlastP (https://www.ncbi.nlm.nih.gov/), Pfam 31.0 web servers (http://pfam.xfam.org/) [26] and InterPro (http:// www.ebi.ac.uk/interpro/) [27] to examine conserved functional domains for putative function assignment. For identifying proteins associated with virulence we used VirulentPred web server (http://203.92.44.117/virulent/index .html) [28].

2.8. Gene Cloning, Expression, and Purification of Recombinant Proteins. Full-length genes of the four selected proteins were amplified directly from M. hyopneumoniae strain 168 genomic DNA using primer pairs in Table 1. Mycoplasmas use UGA as tryptophan codon while E. coli retain it as a stop codon. In order to mutate TGA to TGG and achieve mycoplasma proteins' heterologous expression, we used specific primers (Table 1) to conduct overlapping PCR for sitedirected mutagenesis. Then the products were cloned into pET-28a vector and transformed into E. coli DH5 $\alpha$. After checking the inserts by sequencing, the reconstructed plasmids were transformed into E. coli BL21 (DE3) to express the $\mathrm{N}$-terminal $6 \times$ His-tagged recombinant proteins. Obtained proteins were purified by nickel affinity chromatograph (GE Healthcare, Piscataway, NJ, USA), dialyzed in PBS, and concentrated with Amicon Ultra centrifugal filter units (Millipore, Darmstadt, Germany). Protein concentration was determined by BCA Protein Assay Kit (Beyotime, Nanjing, China), and the purity was verified on $12 \%$ Coomassiestained SDS-PAGE gels.

2.9. Production of Polyclonal Antibodies. Polyclonal antisera were produced in New Zealand White rabbits via four times subcutaneous immunization at 2-week intervals. Rabbits were first immunized with $1 \mathrm{mg}$ of purified proteins mixed with equal volumes of complete Freund's adjuvant (Sigma, St. Louis, MI, USA). The rest three booster immunizations used $1 \mathrm{mg}$ of purified proteins suspended in equal volumes of incomplete Freund's adjuvant (Sigma, St. Louis, MI, USA). Ten days after the last immunization, blood samples were collected via cardiac bleeding and centrifuged to obtain serum.

2.10. Western Blot Analysis. Western workflow utilizing stainfree technology was performed according to the supplier protocol. Samples of 10 ug were separated in $12 \%$ TGX Stain-Free Fastcast acrylamide gels (Bio-Rad, Hercules, CA, USA). After the electrophoresis, gels were placed in the ChemiDoc $^{\mathrm{TM}}$ Touch Imaging System (Bio-Rad, Hercules, CA, USA) and activated for $5 \mathrm{~min}$ with UV treatment to visualize total proteins. Then the proteins were transferred to PVDF membranes. After blocking with $10 \%$ milk for $3 \mathrm{~h}$ at room temperature, membranes were incubated at room temperature for $4 \mathrm{~h}$ with rabbit polyclonal antibodies (1:500) against methylmalonate-semialdehyde dehydrogenase, endo-1,4-beta-glucanase, enolase, and translation elongation factor Tu. Goat anti-rabbit IgGs conjugated with horseradish peroxidase (1:4000; Beyotime, Nanjing, China) were used as secondary antibodies, and, after antibodies incubation, stain-free blot images were captured for total protein loading control and normalization. Then proteins were detected with ClarityTM ECL reagents (Bio-Rad, Hercules, CA, USA), and the intensity values of the target bands were normalized to that of the total proteins in the lane. The $168 / 168 \mathrm{~L}$ intensity ratios were calculated for each protein, and three replicates were subjected to statistical analysis.

\section{Results}

3.1. Global Protein Profiles Overview. To establish more detailed comparable proteome profiles of the virulent strain 168 and its attenuated strain 168L, whole proteins were 
TABLE 1: Primers used for amplication and site-directed mutagenesis.

\begin{tabular}{|c|c|c|c|}
\hline Target & Primers & Sequence $\left(5^{\prime}\right.$ to $\left.3^{\prime}\right)$ & Description \\
\hline \multirow{4}{*}{ Endo-1,4-beta-glucanase } & MHP168_174-F & CGCGGATCCATGTCAATATTAGAAAAAAT & Amplification \\
\hline & MHP168_174-M1R & CGCATTTCCcCAAATTCCGC & $\begin{array}{l}\text { Site directed } \\
\text { mutagenesis }\end{array}$ \\
\hline & MHP168_174-M1F & GCGGAATTTGgGGAAATGCG & $\begin{array}{l}\text { Site directed } \\
\text { mutagenesis }\end{array}$ \\
\hline & MHP168_174-R & CGCCTCGAGTTATTTATATATTAACTC & Amplification \\
\hline \multirow{6}{*}{ Enolase } & MHP168_271-F & CTTGGATCCATGTCAAAAATTACTAAAG & Amplification \\
\hline & MHP168_271-M1R & CTTTTTGACCATAcCAATTATCTGC & $\begin{array}{l}\text { Site directed } \\
\text { mutagenesis }\end{array}$ \\
\hline & MHP168_271-M1F & GCAGATAATTGgTATGGTCAAAAAG & $\begin{array}{l}\text { Site directed } \\
\text { mutagenesis }\end{array}$ \\
\hline & MHP168_271-M2R & GATAAAACCCTGcCAATCAGATTC & $\begin{array}{l}\text { Site directed } \\
\text { mutagenesis }\end{array}$ \\
\hline & MHP168_271-M2F & GAATCTGATTGgCAGGGTTTTATC & $\begin{array}{l}\text { Site directed } \\
\text { mutagenesis }\end{array}$ \\
\hline & MHP168_271-R & TATCTCGAGCTATTTTTTTAAGTTATAAAAAACT & Amplification \\
\hline \multirow{2}{*}{$\begin{array}{l}\text { Translation elongation } \\
\text { factor Tu }\end{array}$} & MHP168_533-F & CTCGGATCCATGGCAGTTGTTAAAACG & Amplification \\
\hline & MHP168_533-R & CCGCTCGAGTTATTTAATAATTTCGGT & Amplification \\
\hline \multirow{12}{*}{$\begin{array}{l}\text { Methylmalonate- } \\
\text { semialdehyde } \\
\text { dehydrogenase }\end{array}$} & MHP168_244-F & CGGGGATCCATGAATTTTAAAAGAAATTAC & Amplification \\
\hline & MHP168_244-M1R & CATTTGGAATTGAcCAATTTGGCAC & $\begin{array}{l}\text { Site directed } \\
\text { mutagenesis }\end{array}$ \\
\hline & MHP168_244-M1F & GTGCCAAATTGgTCAATTCCAAATG & $\begin{array}{l}\text { Site directed } \\
\text { mutagenesis }\end{array}$ \\
\hline & MHP168_244-M2R & CGGCTTGTTTcCAAAGATCAG & $\begin{array}{l}\text { Site directed } \\
\text { mutagenesis }\end{array}$ \\
\hline & MHP168_244-M2F & CTGATCTTTGgAAACAAGCCG & $\begin{array}{l}\text { Site directed } \\
\text { mutagenesis }\end{array}$ \\
\hline & MHP168_244-M3R & GAATCTCTGAcCAGTCAATAATTG & $\begin{array}{l}\text { Site directed } \\
\text { mutagenesis }\end{array}$ \\
\hline & MHP168_244-M3F & CAATTATTGACTGgTCAGAGATTC & $\begin{array}{l}\text { Site directed } \\
\text { mutagenesis }\end{array}$ \\
\hline & MHP168_244-M4R & AATCAAATTAGTcCAGAAATTAATACTGG & $\begin{array}{l}\text { Site directed } \\
\text { mutagenesis }\end{array}$ \\
\hline & MHP168_244-M4F & CCAGTATTAATTTCTGgACTAATTTGATT & $\begin{array}{l}\text { Site directed } \\
\text { mutagenesis }\end{array}$ \\
\hline & MHP168_244-M5R & CTTCCGGGTTcCATTTTGTAG & $\begin{array}{l}\text { Site directed } \\
\text { mutagenesis }\end{array}$ \\
\hline & MHP168_244-M5F & CTACAAAATGgAACCCGGAAG & $\begin{array}{l}\text { Site directed } \\
\text { mutagenesis }\end{array}$ \\
\hline & MHP168_244-R & CTTCTCGAGTTATGACATcCAATCCTG & $\begin{array}{l}\text { Amplification and site } \\
\text { directed mutagenesis }\end{array}$ \\
\hline
\end{tabular}

extracted from the two strains, digested and labeled with iTRAQ reagents, followed by downstream analysis LCMS/MS.

Results of the iTRAQ assay showed that 489 proteins, $70 \%$ (489/695) of the coding sequences in M. hyopneumoniae, were identified from 30,214 spectra from the whole output of 322,266 spectra with an FDR of 1\% (Table S1) [15]. The molecular weights of most of the identified proteins ranged between 10 and $60 \mathrm{kDa}(68 \%$, Figure 1(a)). 50.5\% of the identified proteins possessed sequence coverage of the identified peptides of higher than 30\% (Figure 1(b)).
Of the 489 proteins identified, 273 proteins were annotated into 9 groups based on the KEGG categories. The categories with the highest abundance were translation (70 proteins), carbohydrate metabolism (45 proteins), replication and repair (41 proteins), nucleotide metabolism (40 proteins), and membrane transport (40 proteins) (Figure 2(a)). Meanwhile, further classification indicated that the top ten pathways in which the identified proteins were involved were ribosome biosynthesis, microbial metabolism in diverse environments, biosynthesis of secondary metabolites, biosynthesis of antibiotics, carbon 


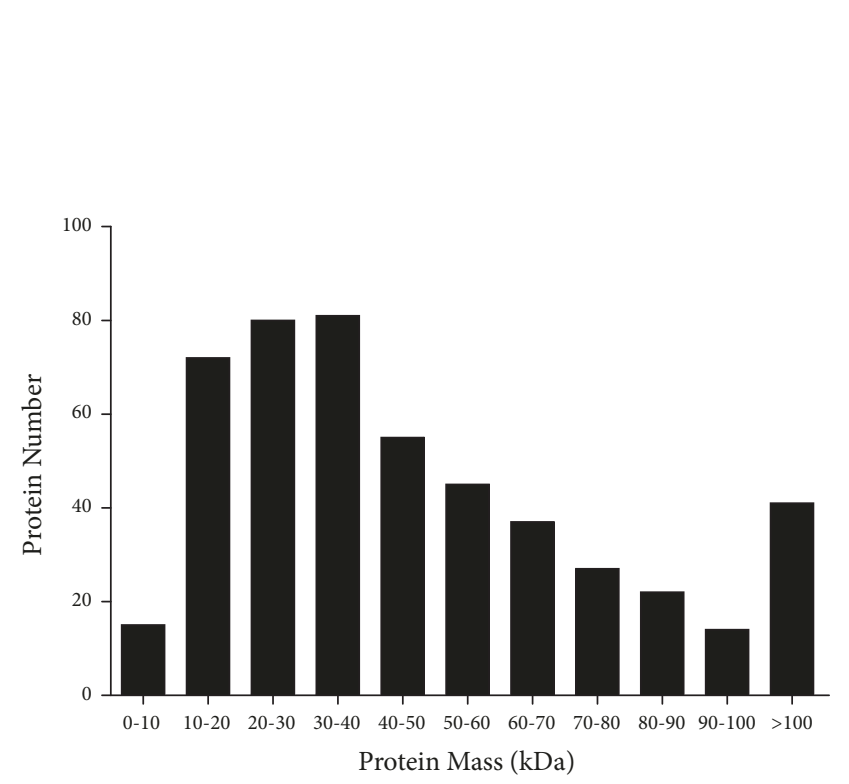

(a)

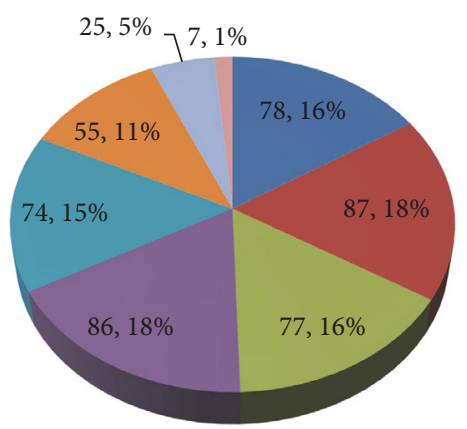

$=0-10 \%$
$=10 \%-20 \%$
$=20 \%-30 \%$
$=30 \%-40 \%$
$=40 \%-50 \%$
$=50 \%-60 \%$
$=60 \%-70 \%$
$-70 \%-100 \%$

(b)

Figure 1: Overview of all proteins identified in M. hyopneumoniae. (a) Distribution of proteins of different molecular weights. (b) Coverage of proteins by LC-MS/MS identified peptides.

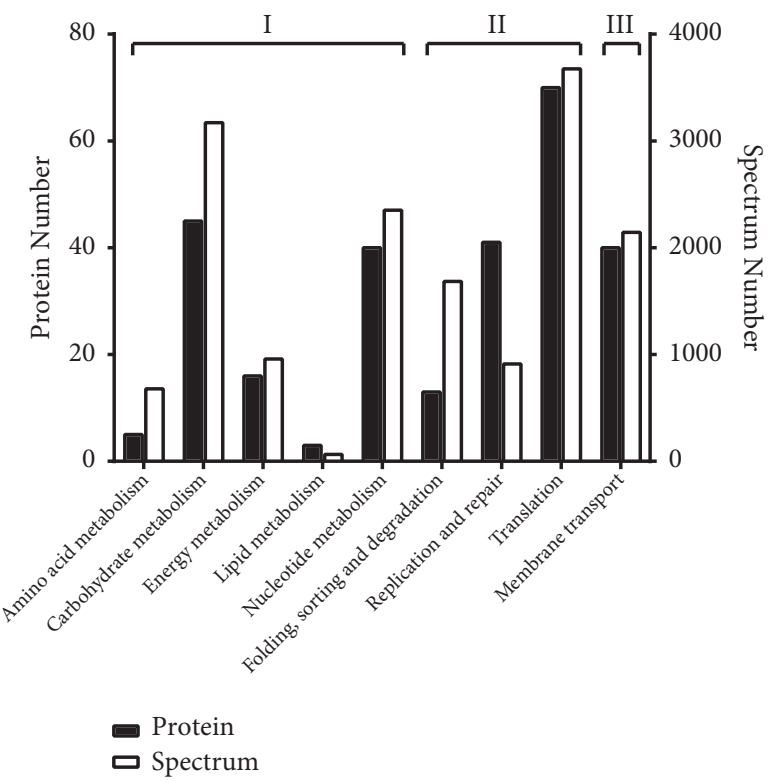

(a)

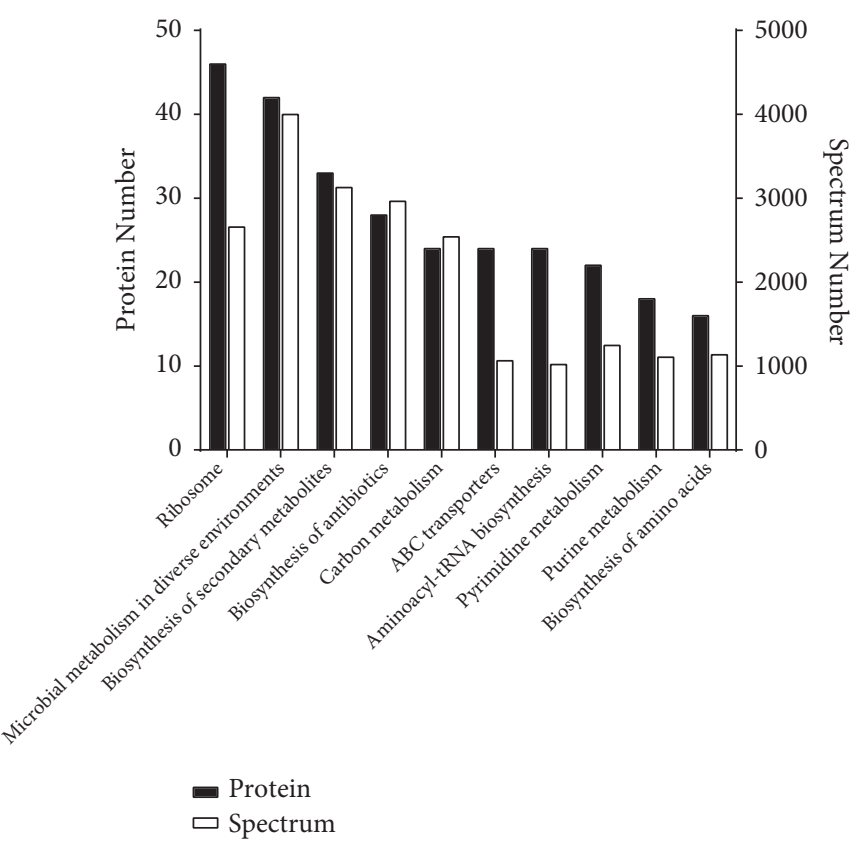

(b)

FIGURE 2: KEGG classification of the annotated proteins and corresponding spectra in quantitative proteome of Mycoplasma hyopneumoniae 168 and 168L. (a) KEGG classification of the annotated proteins and corresponding spectra based on secondary pathway hierarchy: (I) metabolism; (II) genetic information and processing; (III) environmental information and processing. (b) The 10 most highly represented KEGG pathways of the annotated proteins.

metabolism, ABC transporters, aminoacyl-tRNA biosynthesis, pyrimidine metabolism, purine metabolism, and biosynthesis of amino acids (Figure 2(b)).
3.2. Differentially Expressed Proteins. We detected and quantified 489 proteins, of which 35 were more abundant in the Mhp168 strain and 35 in the Mhp168L strain, based on having 


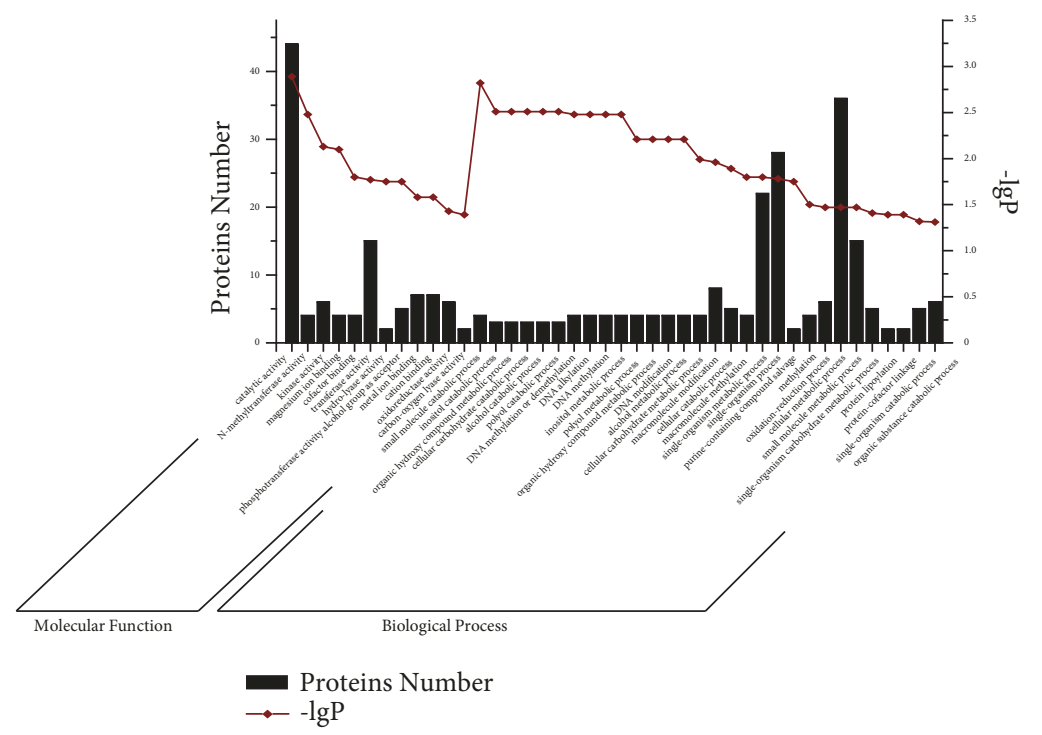

(a)

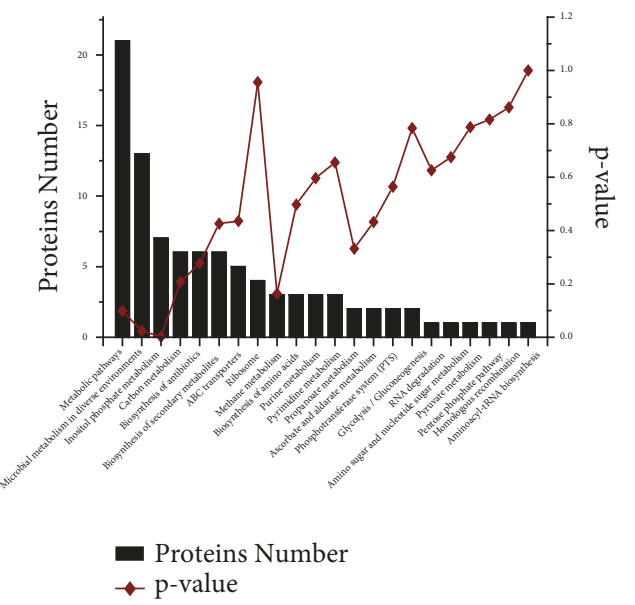

(b)

FIGURE 3: Functional categories of differentially expressed proteins. (a) GO term enrichment analysis of the annotated differentially expressed proteins for the categories "molecular function" and "biological process". (b) Pathway enrichment analysis of the annotated differentially expressed proteins.

a $\log 2$ ratio $\geq 0.585$ or $\leq-0.585$ and a statistically significant differences at $\mathrm{p}<0.05$ (Table 2).

Gene Ontology (GO) enrichment analysis was then performed for the differentially expressed proteins for the categories "molecular function" (F), "cellular components" (C), and "biological process" (P) (Table S2). Figure 3(a) shows the result of the enrichment analysis for these functions (GO terms). A total of $12 \mathrm{GO}$ terms were enriched for molecular function and 30 for biological processes, while there's no statistically significant results for cellular components. For the GO category "molecular function", significant synthesis of the proteins related to catalytic activity were detected. In addition, the GO terms "N-methyltransferase activity", "kinase activity", and "magnesium ion binding" were also highly enriched. The highest enrichment for biological processes was associated with small molecule catabolism. In addition, the GO terms "inositol catabolic process", "organic hydroxy compound catabolic process", "cellular carbohydrate catabolic process", "alcohol catabolic process", "polyol catabolic process", "DNA methylation or demethylation", "DNA alkylation", "DNA methylation", and "inositol metabolic process" were also highly enriched.

To examine which biological pathways were apparently altered, we carried out a pathway analysis. Enriched pathways were grouped into 2 categories with $\mathrm{P}$ value $<0.05$ (Table S3, Figure $3(\mathrm{~b})$ ). The two pathways were involved in microbial metabolism in diverse environments and in inositol phosphate metabolism.

3.3. Expression of Recombinant Proteins and Preparation of Polyclonal Antibodies. Four differently expressed proteins, endo-1,4-beta-glucanase, enolase, translation elongation factor $\mathrm{Tu}$, and methylmalonate-semialdehyde dehydrogenase were chosen to verify the proteomic differences. Within the virulent strain 168 samples, endo-1,4-beta-glucanase, enolase, and translation elongation factor $\mathrm{Tu}$ were more abundant, which might conduce to the virulence of M. hyopneumoniae. All these three proteins are cytosolic enzymes, lacking transmembrane domains or traditional signal sequences (Table 3), yet intensive researches during the past years have suggested that they could be detected on microbe surface and moonlight as adhesins [29-34]. On one hand we expect to obtain sera to validate the comparative results and on the other hand we are calculated to conduct further experiments around these proteins. We expressed these recombinant proteins in prokaryotic system (Figure 4(a)) then got the rabbit sera against the proteins, respectively (Figure 4(b)).

3.4. Validation of Selected Proteins by Western Blot. We performed western blot analyses using a stain-free technology to assess the levels of four selected differentially expressed proteins. As shown in Figure 5, the alterations in expression levels of these proteins between strain 168 and 168L were consistent with the results from quantitative proteomic analysis, suggesting the credibility of our proteomic data.

\section{Discussion}

In this study, we compared the protein profiles of the pathogenic M. hyopneumoniae strain 168 and its highly passaged attenuated strain 168L using iTRAQ strategy for the first time. We identified 70 differentially expressed proteins to mine candidate virulence determinants and proteins or biological processes leading to attenuation. 
TABLE 2: Proteins differentially expressed between the compared samples (M. hyopneumoniae strain 168 and strain 168L).

\begin{tabular}{|c|c|c|c|c|c|c|}
\hline Identified Proteins & Accession Number & Gene_locus & Gene & $\begin{array}{c}\log 2 \text { ratios } \\
(168 / 168 \mathrm{~L}) \\
\end{array}$ & $\begin{array}{l}\text { Unique } \\
\text { Peptide }\end{array}$ & $\begin{array}{c}\text { Percentage } \\
\text { Coverage }\end{array}$ \\
\hline \multicolumn{7}{|c|}{ proteins which were more abundant in $168 \mathrm{~L}$} \\
\hline Myo-inositol catabolism protein & ADQ90457 & MHP168_246 & - & -3.04 & 10 & $45 \%$ \\
\hline Myo-inositol 2-dehydrogenase & ADQ90458 & MHP168_247 & - & -2.89 & 16 & $43 \%$ \\
\hline $\begin{array}{l}\text { Periplasmic sugar-binding } \\
\text { protein }\end{array}$ & ADQ90463 & MHP168_252 & rbsB & -2.76 & 21 & $61 \%$ \\
\hline $\begin{array}{l}\text { Methylmalonate-semialdehyde } \\
\text { dehydrogenase }\end{array}$ & ADQ90455 & MHP168_244 & - & -2.53 & 21 & $48 \%$ \\
\hline Serine hydroxymethyltransferase & ADQ90454 & MHP168_243 & glyA & -2.4 & 14 & $36 \%$ \\
\hline $\begin{array}{l}\text { 5-Dehydro-2- } \\
\text { deoxygluconokinase }\end{array}$ & ADQ90456 & MHP168_245 & iolC & -2.25 & 11 & $30 \%$ \\
\hline Myo-inositol 2-dehydrogenase & ADQ90464 & MHP168_253 & - & -2.07 & 11 & $39 \%$ \\
\hline Myo-inositol catabolism & ADQ90459 & MHP168_248 & iolD & -2.04 & 17 & $27 \%$ \\
\hline Myo-inositol catabolism protein & ADQ90460 & MHP168_249 & iolE & -2.04 & 5 & $20 \%$ \\
\hline $\begin{array}{l}\text { Site-specific } \\
\text { DNA-methyltransferase }\end{array}$ & ADQ90525 & MHP168_318 & $\bmod$ & -1.65 & 7 & $27 \%$ \\
\hline Hypothetical protein & ADQ90289 & MHP168_066 & - & -1.54 & 5 & $5.80 \%$ \\
\hline $\begin{array}{l}\text { Ribose ABC transport } \\
\text { ATP-binding protein }\end{array}$ & ADQ90461 & MHP168_250 & mglA & -1.39 & 14 & $35 \%$ \\
\hline Lipoprotein & ADQ90594 & MHP168_392 & - & -1.21 & 36 & $54 \%$ \\
\hline Putative uncharacterized protein & ADQ90727 & MHP168_531 & - & -1.21 & 63 & $33 \%$ \\
\hline Protein P97-copy 2 & ADQ90409 & MHP168_195 & - & -1.12 & 34 & $38 \%$ \\
\hline Glucose kinase & ADQ90722 & MHP168_526 & glcK & -1.04 & 7 & $25 \%$ \\
\hline Protein p97, cilium adhesin & ADQ90328 & MHP168_110 & - & -1.03 & 70 & $64 \%$ \\
\hline $\begin{array}{l}\text { tRNA uridine } \\
\text { 5-carboxymethylaminomethyl } \\
\text { modification enzyme mnmG }\end{array}$ & ADQ90231 & MHP168_003 & $\operatorname{gid} A$ & -1.01 & 12 & $20 \%$ \\
\hline Neutrophil activating factor & ADQ90913 & MHP168_736 & - & -0.98 & 6 & $41 \%$ \\
\hline $\begin{array}{l}\text { Xylose ABC transporter } \\
\text { ATP-binding protein }\end{array}$ & ADQ90719 & MHP168_523 & xylG & -0.93 & 15 & $35 \%$ \\
\hline $\begin{array}{l}\text { Xylose } \mathrm{ABC} \text { transporter } \\
\text { permease protein }\end{array}$ & ADQ90720 & MHP168_524 & xylH & -0.93 & 4 & $8.20 \%$ \\
\hline $\begin{array}{l}\text { ABC transporter ATP-binding } \\
\text { protein }\end{array}$ & ADQ90246 & MHP168_019 & - & -0.91 & 6 & $8.50 \%$ \\
\hline Lipoprotein & ADQ90595 & MHP168_393 & - & -0.88 & 9 & $28 \%$ \\
\hline GTPase obg & ADQ90265 & MHP168_042 & obgE & -0.88 & 6 & $17 \%$ \\
\hline Protein P102-copy 2 & ADQ90410 & MHP168_196 & - & -0.83 & 21 & $25 \%$ \\
\hline 50S ribosomal protein L24 & ADQ90339 & MHP168_121 & $\mathrm{rplX}$ & -0.81 & 6 & $48 \%$ \\
\hline $\begin{array}{l}\text { Heat-inducible transcription } \\
\text { repressor hrcA }\end{array}$ & ADQ90238 & MHP168_011 & hrcA & -0.78 & 13 & $36 \%$ \\
\hline 50S ribosomal protein L23 & ADQ90331 & MHP168_113 & rplW & -0.77 & 11 & $56 \%$ \\
\hline Thioredoxin & ADQ90613 & MHP168_411 & - & -0.77 & 11 & $91 \%$ \\
\hline Putative uncharacterized protein & ADQ90524 & MHP168_317 & - & -0.76 & 13 & $16 \%$ \\
\hline DNA topoisomerase I & ADQ90512 & MHP168_305 & topA & -0.71 & 16 & $28 \%$ \\
\hline 50S ribosomal protein L14 & ADQ90338 & MHP168_120 & $\mathrm{rplN}$ & -0.71 & 10 & $64 \%$ \\
\hline $\begin{array}{l}\text { Holliday junction } \\
\text { ATP-dependent DNA helicase } \\
\text { ruvA }\end{array}$ & ADQ90632 & MHP168_430 & ruvA & -0.67 & 8 & $36 \%$ \\
\hline $\begin{array}{l}\text { Transcription } \\
\text { termination-antitermination } \\
\text { factor nusA } \\
\end{array}$ & ADQ90786 & MHP168_593 & nusA & -0.65 & 21 & $34 \%$ \\
\hline 50 S ribosomal protein L3 & ADQ90329 & MHP168_111 & $\mathrm{rplC}$ & -0.6 & 14 & $58 \%$ \\
\hline
\end{tabular}


TABle 2: Continued.

\begin{tabular}{|c|c|c|c|c|c|c|}
\hline Identified Proteins & Accession Number & Gene_locus & Gene & $\begin{array}{l}\log 2 \text { ratios } \\
(168 / 168 \mathrm{~L})\end{array}$ & $\begin{array}{l}\text { Unique } \\
\text { Peptide }\end{array}$ & $\begin{array}{c}\text { Percentage } \\
\text { Coverage }\end{array}$ \\
\hline \multicolumn{7}{|c|}{ proteins which were more abundant in 168} \\
\hline Triacylglycerol lipase & ADQ90483 & MHP168_274 & lip & 0.59 & 13 & $46 \%$ \\
\hline Putative uncharacterized protein & ADQ90691 & MHP168_495 & - & 0.59 & 8 & $30 \%$ \\
\hline Enolase & ADQ90480 & MHP168_271 & eno & 0.61 & 14 & $48 \%$ \\
\hline Translation elongation factor $\mathrm{Tu}$ & ADQ90729 & MHP168_533 & tuf & 0.61 & 23 & $66 \%$ \\
\hline $\begin{array}{l}\text { Hypoxanthine } \\
\text { phosphoribosyltransferase }\end{array}$ & ADQ90492 & MHP168_283 & hpt & 0.61 & 9 & $50 \%$ \\
\hline Transport protein sgaT & ADQ90622 & MHP168_420 & ulaA & 0.62 & 7 & $13 \%$ \\
\hline $\begin{array}{l}\text { Cation-transporting P-type } \\
\text { ATPase }\end{array}$ & ADQ90498 & MHP168_289 & pacL & 0.63 & 8 & $13 \%$ \\
\hline Hypothetical protein & ADQ90530 & MHP168_323 & - & 0.63 & 5 & $14 \%$ \\
\hline Putative uncharacterized protein & ADQ90824 & MHP168_634 & - & 0.66 & 22 & $28 \%$ \\
\hline Putative uncharacterized protein & ADQ90745 & MHP168_549 & - & 0.68 & 11 & $46 \%$ \\
\hline Acetate kinase AckA & ADQ90711 & MHP168_515 & ackA & 0.69 & 17 & $54 \%$ \\
\hline Cysteinyl-tRNA synthetase & ADQ90838 & MHP168_650 & cysS & 0.69 & 7 & $15 \%$ \\
\hline Putative uncharacterized protein & ADQ90859 & MHP168_673 & - & 0.7 & 11 & $28 \%$ \\
\hline $\begin{array}{l}\text { Pts system, lichenan-specific IIa } \\
\text { component }\end{array}$ & ADQ90264 & MHP168_041 & licA & 0.71 & 9 & $33 \%$ \\
\hline $\begin{array}{l}\text { Probable O-sialoglycoprotein } \\
\text { endopeptidase }\end{array}$ & ADQ90833 & MHP168_644 & $\mathrm{gcp}$ & 0.73 & 10 & $37 \%$ \\
\hline CTP synthase & ADQ90509 & MHP168_302 & pyrG & 0.74 & 14 & $25 \%$ \\
\hline Lipoate-protein ligase A & ADQ90531 & MHP168_324 & lplA-1 & 0.75 & 14 & $33 \%$ \\
\hline $\begin{array}{l}\text { ABC transporter } \\
\text { ATP-binding-Pr1 }\end{array}$ & ADQ90875 & MHP168_691 & prl & 0.75 & 7 & $16 \%$ \\
\hline Hypothetical protein & ADQ90910 & MHP168_731 & - & 0.76 & 4 & $35 \%$ \\
\hline Thymidine kinase & ADQ90808 & MHP168_618 & $\mathrm{tdk}$ & 0.78 & 8 & $40 \%$ \\
\hline Lipoate-protein ligase A & ADQ90484 & MHP168_275 & lplA & 0.78 & 5 & $16 \%$ \\
\hline $\begin{array}{l}\text { Purine-nucleoside } \\
\text { phosphorylase }\end{array}$ & ADQ90309 & MHP168_087 & deoD & 0.8 & 7 & $29 \%$ \\
\hline Endo-1,4-beta-glucanase & ADQ90389 & MHP168_174 & - & 0.84 & 20 & $64 \%$ \\
\hline $\begin{array}{l}\text { NADH dependent flavin } \\
\text { oxidoreductase }\end{array}$ & ADQ90532 & MHP168_325 & baiH & 0.85 & 4 & $11 \%$ \\
\hline $\mathrm{ABC}$ transporter protein & ADQ90806 & MHP168_616 & - & 0.87 & 6 & $11 \%$ \\
\hline $\begin{array}{l}\text { Sugar ABC transporter } \\
\text { ATP-binding protein }\end{array}$ & ADQ90805 & MHP168_615 & - & 0.9 & 10 & $26 \%$ \\
\hline MG2+ ion transporter & ADQ90693 & MHP168_497 & mgtE & 0.9 & 9 & $23 \%$ \\
\hline Ribonuclease III & ADQ90602 & MHP168_400 & rnc & 0.94 & 9 & $34 \%$ \\
\hline $\begin{array}{l}\text { Ribose-phosphate } \\
\text { pyrophosphokinase }\end{array}$ & ADQ90852 & MHP168_664 & prsA & 0.98 & 12 & $39 \%$ \\
\hline Glycerol transporter subunit A & ADQ90619 & MHP168_417 & gtsA & 1.13 & 4 & $11 \%$ \\
\hline Putative uncharacterized protein & ADQ90827 & MHP168_638 & - & 1.16 & 4 & $7.50 \%$ \\
\hline hypothetical protein & ADQ90324 & MHP168_104 & - & 1.59 & 19 & $23 \%$ \\
\hline Glycerol kinase & ADQ90587 & MHP168_385 & glpK & 1.59 & 22 & $49 \%$ \\
\hline Lipoprotein & ADQ90620 & MHP168_418 & - & 1.7 & 31 & $55 \%$ \\
\hline $\begin{array}{l}\text { PTS system galactitol-specific } \\
\text { enzyme IIB component }\end{array}$ & ADQ90760 & MHP168_564 & - & 1.78 & 4 & $57 \%$ \\
\hline
\end{tabular}


TABLE 3: Bioinformatic analyses for the proteins selected for validation.

\begin{tabular}{|c|c|c|c|c|c|c|}
\hline Protein & $\begin{array}{c}\text { Number of } \\
\text { amino acids }\end{array}$ & $\begin{array}{c}\text { Molecular } \\
\text { weight }\end{array}$ & Theoretical PI & $\begin{array}{c}\text { Number of } \\
\text { predicted TMHs }\end{array}$ & $\begin{array}{c}\text { Signal } \\
\text { peptide }\end{array}$ & $\begin{array}{c}\text { Number of TGA } \\
\text { codons }\end{array}$ \\
\hline Endo-1,4-beta-glucanase & 356 aа & $39.2 \mathrm{kDa}$ & 6.21 & 0 & No & 1 \\
\hline Enolase & 452 aa & $49.5 \mathrm{kDa}$ & 5.83 & 0 & No & 2 \\
\hline $\begin{array}{l}\text { Translation elongation } \\
\text { factor } \mathrm{Tu}\end{array}$ & 402 aa & $44.1 \mathrm{kDa}$ & 5.61 & 0 & No & 0 \\
\hline $\begin{array}{l}\text { Methylmalonate- } \\
\text { semialdehyde } \\
\text { dehydrogenase }\end{array}$ & 489 aa & $53.9 \mathrm{kDa}$ & 8.46 & 0 & No & 6 \\
\hline
\end{tabular}

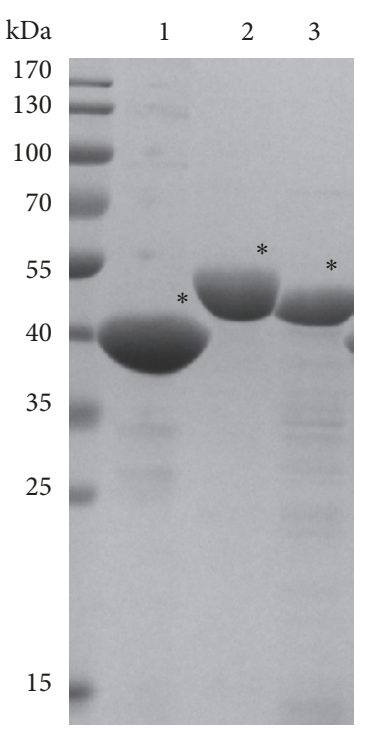

(a)
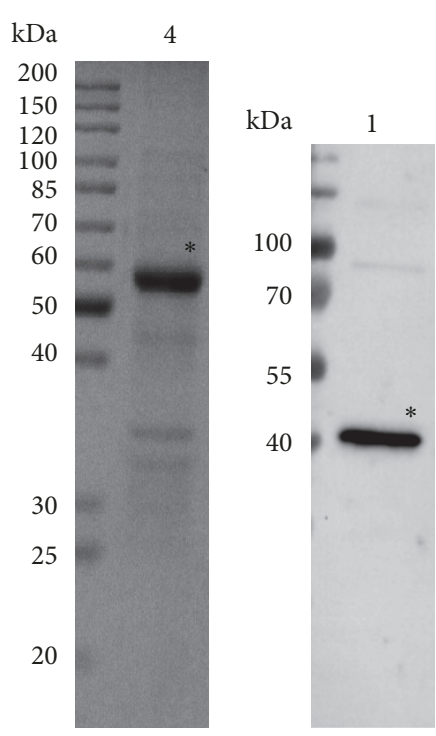
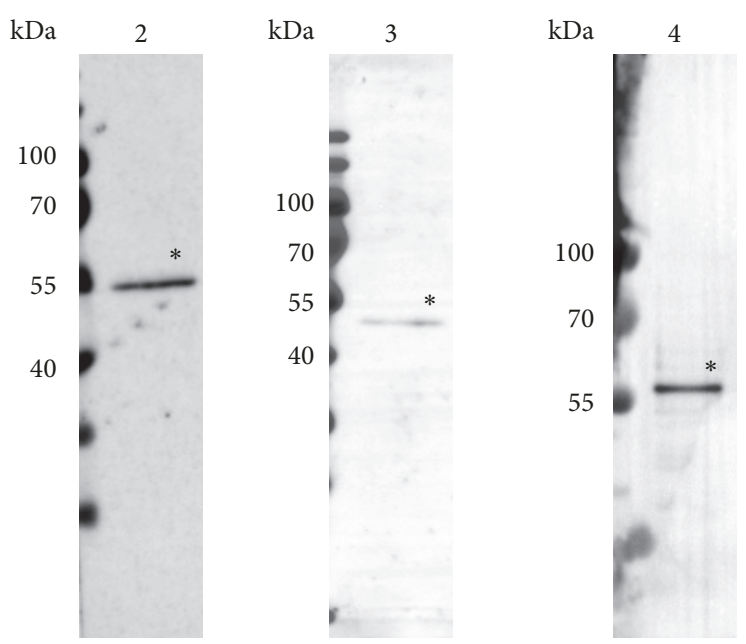

FIGURE 4: The expression of recombinant proteins and their reactivity with corresponding antisera. (a) Coomassie blue stained SDS-PAGE gel of purified recombinant proteins. (b) Western bolt analyses of purified proteins using their corresponding antisera. Lane 1, endo-1,4-betaglucanase; lane 2, enolase; lane 3, translation elongation factor Tu; and lane 4, methylmalonate-semialdehyde dehydrogenase.

4.1. Proteins Involved in Inositol Phosphate Metabolism. Among all the sequenced mycoplasma species, $M$. hyopneumoniae is the only one having a gene cluster for myo-inositol utilization [35]. A previous report, based on the reconstruction of a genome-scaled metabolic model for three mycoplasmas in silico, suggested that the myo-inositol metabolism may be one of the reasons for the high virulence of $M$. hyopneumoniae compared to that of $M$. flocculare and $M$. hyorhinis [35]. In our study, seven related enzymes of inositol phosphate metabolism, namely, myo-inositol 2-dehydrogenase (MHP168_253), myo-inositol catabolism protein (MHP168_246), myoinositol 2-dehydrogenase (MHP168_247), methylmalonatesemialdehyde dehydrogenase (MHP168_244), 5-dehydro2-deoxygluconokinase (IolC), myo-inositol catabolism (IolD), and myo-inositol catabolism protein (IolE), were more abundant in the vaccine strain. These proteins covered all the enzymes comprising the classical myoinositol bacterial catabolic pathway in M. hyopneumoniae, with the exception of the enzyme acting as 5-dehydro-2deoxyphosphogluconate aldolase (IolJ) whose gene was also absent in its genome. Nevertheless, Ferrarini et al. [36] hypothesized that one gene copy among those annotated as fructose-biphosphate aldolase (Fba) from M. hyopneumoniae might function as IolJ from other organisms and confirmed that $M$. hyopneumoniae had been able to utilize myo-inositol from the culture medium.

The increments of those protein levels might facilitate the catabolism of myo-inositol to produce dihydroxyacetonephosphate (DHAP) and acetyl-coenzyme A (CoA). DHAP can enter glycolysis while acetyl CoA can be widely used in macromolecular biosynthesis and energy production to support cell growth and proliferation. The presence of inositol in mammalian hosts' bloodstream [37] and the degradation of phosphatidylinositol from host' pulmonary surfactant [38] make myo-inositol available for the strains in vivo. Considering the fact that myo-inositol has been one stable readily abundant component in the culture medium containing swine serum, we may assume that M. hyopneumoniae retains the ability of degrading myo-inositol in vivo, then the capability is increased with passage in vitro. The vaccine strain might have developed an enhanced ability to cope with 
Endo-1,4-beta-glucanase

Stain free blot of total proteins

Enolase

Stain free blot of total proteins

Translation elongation factor $\mathrm{Tu}$

Stain free blot of total proteins

Methylmalonate-semialdehyde dehydrogenase

Stain free blot of total proteins
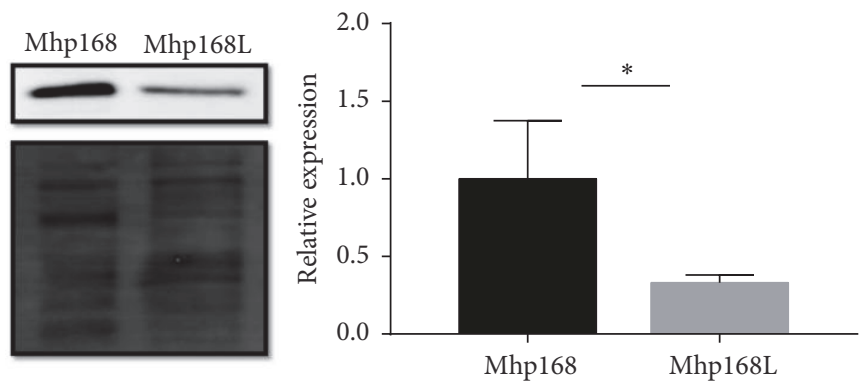

(a)
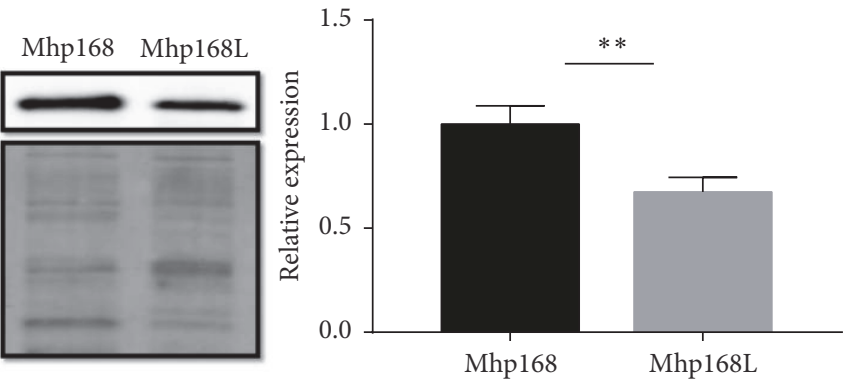

(b)
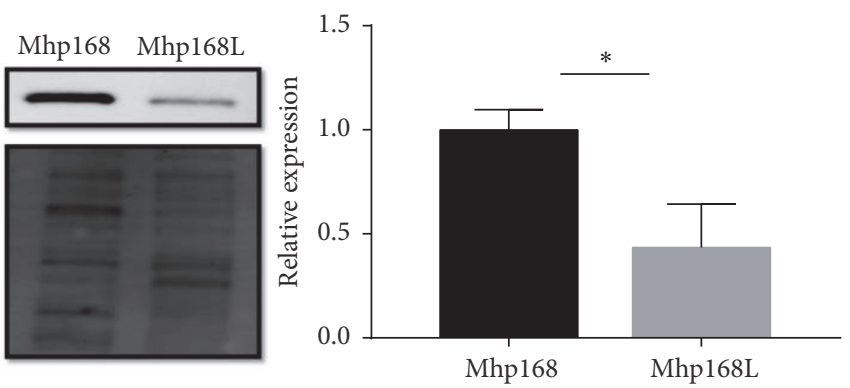

(c)
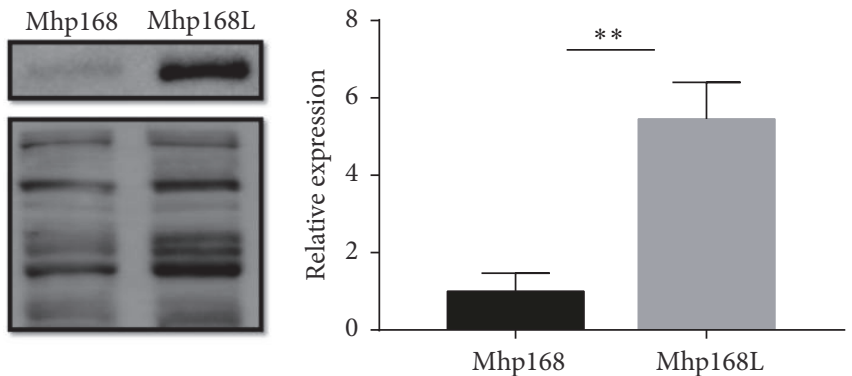

(d)

FIGURE 5: Western blot analyses of differentially expressed proteins using stain-free technology. (a) Endo-1,4-beta-glucanase, (b) enolase, (c) translation elongation factor $\mathrm{Tu}$, and (d) methylmalonate-semialdehyde dehydrogenase. Left: immunoblot images for selected proteins. Total protein loading on the same membrane was used as control. Right: the expression level of the selected protein in strain 168L was presented as the fold change between 168L and 168. Data are present as mean $\pm \mathrm{SD}(\mathrm{n}=3) . * \mathrm{p}<0.05, * * \mathrm{p}<0.01$, Student $\mathrm{t}$-test.

differences in environmental carbon sources. However, the myo-inositol utilization gene cluster existed in both strains, and there were no genetic variations in the coding sequences or intergenic regions of those genes [5]. It may be suggested that strains which possess this gene cluster could express it constitutively, while the regulatory mechanism for the enhancements is unclear and still need future research.
4.2. Proteins Involved in Nucleotide Metabolism. M. hyopneumoniae cannot synthesize purines and pyrimidines de novo. However, this organism is able to take up exogenous nucleobases and nucleosides, as well as those produced internally by DNA and RNA degradation, and then synthesize nucleotides through salvage pathways and interconversions [39]. In the virulent strain, the upregulation of transport 


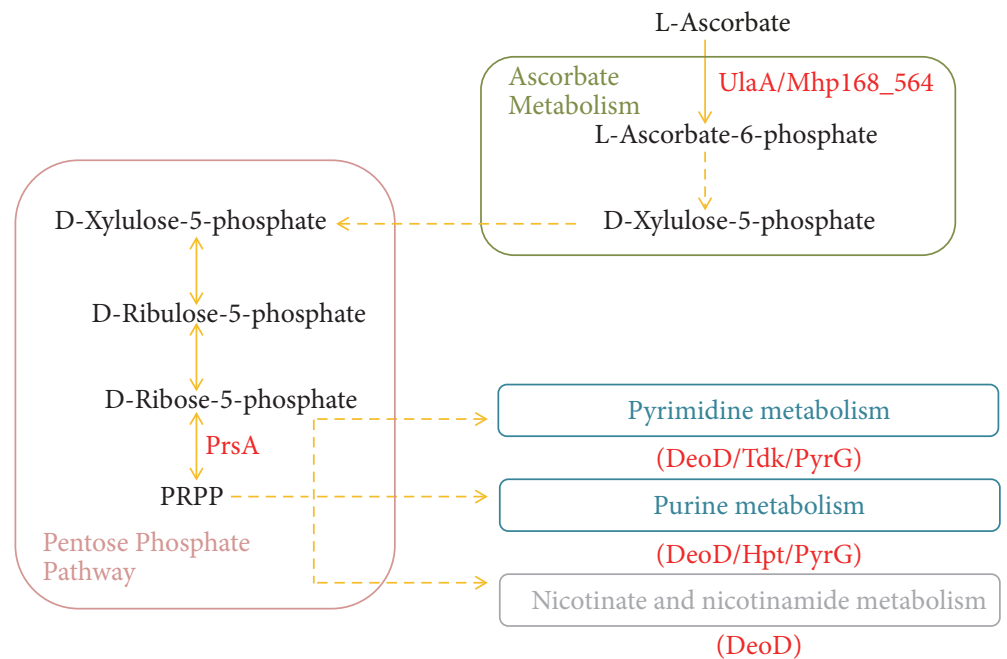

FIGURE 6: Metabolic pathways for ascorbate, pentose phosphate, nucleotide, and nicotinate related to differentially expressed proteins between M. hyopneumoniae strain 168 and 168L. Red text indicates the upregulated proteins in strain 168 compared with that of 168L.

protein SgaT (UlaA) and PTS system galactitol-specific enzyme IIB component (MHP168_564) participated in ascorbate transport suggests the enhanced influx of D-Xylulose5-phosphate (Xyl5P) through ascorbate metabolism into the pentose phosphate pathway to generate phosphoribosyl pyrophosphate (PRPP) (Figure 6). Meanwhile, the increased expression of ribose-phosphate pyrophosphokinase (PrsA) of the pentose phosphate pathway, catalyzing ribose-5phosphate (R5P) to PRPP, implies the enriched production of PRPP which is a key intermediate to synthesize purine and pyrimidine nucleotides, as well as nicotinamide adenine dinucleotide (NAD) (Figure 6) [40]. We found that in our data four enzymes participated in nucleoside metabolism: purinenucleoside phosphorylase (DeoD), hypoxanthine-guanine phosphoribosyl transferase (Hpt), thymidine kinase (Tdk), and CTP synthase (PyrG), all upregulated in the virulent strain. NAD is required for the generation of NADPH that responds to oxidative burst, while synthesis of nucleotides can also promote DNA damage repair caused by oxidative stress [41]. Thus, the increased synthesis of PRPP, NAD, and the upregulation of the nucleotide synthesis in virulent strain 168 could be identified as defense to reactive oxygen species (ROS) damage, fitting well with the idea of an elevated virulence.

4.3. Potential Virulence Factors. Mycoplasmas contain a range of virulence factors in their pathogenic machinery, including enzymes, transporters, transcriptional regulators, lipoproteins [42]. Among the overrepresented proteins in virulent strain 168 , proteins associated with virulence usually play important roles in M. hyopneumoniae offence and defense, meriting more attention. To predict putative novel virulence factors and search for potential drug/vaccine targets, we used VirulentPred to perform the in silico analysis for the 35 upexpressed proteins in the virulent strain 168. The server categorized 18 proteins to be associated with virulence. Out of these, 10 proteins are ones with known functions, and the others are termed as "hypothetical" or "uncharacterized". As a complement to the bioinformatics analyses, we also searched manually the 35 proteins and/or their paralogues for the references that support their virulence-related activities in M. hyopneumoniae, or in other pathogens. Then additional 8 proteins classified as "nonvirulent" were recruited into the group of putative virulence proteins. The results are summarized in Table 4 and the listed proteins are discussed in the main text below.

Lipoproteins. Three lipoproteins were identified in this study. MHP168_392 and MHP168_393 were downexpressed and MHP168_418 were upexpressed in the virulent strain 168 . Most lipoproteins are surface exposed and important components of mycoplasma membranes, and some in M. hyopneumoniae have been identified to play important roles in pathogenesis [43-49]. Mhp378, a homolog of MHP168_392 from M. hyopneumoniae 232, has been identified as a speciesspecific, highly immunogenic membrane-associated protein [50]. The homolog of MHP168_393 in M. hyopneumoniae $232(\mathrm{mhp} 379)$ is a surface-exposed exonuclease with probable function in importing nucleic acid precursors [47]. Furthermore, surface located MHP168_418 is shown with the ability to induce apoptosis of porcine peripheral blood mononuclear cells in vitro [51]. M. hyopneumoniae usually cannot employ the similar mechanisms used by other mycoplasma species to generate antigenic diversity through genetic variation [52]. Nonetheless, the posttranslational proteolytic processing, which targeted mycoplasmal membrane lipoproteins and other surface-associated proteins, could create a dynamic surface topograph [53]. The identified lipoproteins with differential expression levels, as well as their probable posttranslational cleavage, could lead to antigenic variations, thereby affecting its immune evasion in host.

Adhesion-Related Proteins. The adherence of M. hyopneumoniae to ciliated respiratory epithelium is mainly mediated 
TABLE 4: VirulentPred screening of the 35 overrepresented proteins in M. hyopneumoniae 168. References supporting the association with virulence are included.

\begin{tabular}{|c|c|c|c|}
\hline Identified Proteins & Accession Number & Prediction results & Reference \\
\hline Putative uncharacterized protein & ADQ90691 & Virulent & $\begin{array}{c}\text { Okan et al. 2013; Shahbaaz et } \\
\text { al. } 2015\end{array}$ \\
\hline Hypothetical protein & ADQ90530 & Virulent & Cheng et al. 2017 \\
\hline Putative uncharacterized protein & ADQ90824 & Virulent & $\begin{array}{c}\text { Heithoff et al. 1999; Shahbaaz } \\
\text { et al. } 2015\end{array}$ \\
\hline Putative uncharacterized protein & ADQ90745 & Virulent & Gay et al. 1991; Kobe et al. 2001 \\
\hline Cysteinyl-tRNA synthetase & ADQ90838 & Virulent & \\
\hline Putative uncharacterized protein & ADQ90859 & Virulent & $\begin{array}{c}\text { Cheng et al. 1996; Monnerat et } \\
\text { al. } 1999\end{array}$ \\
\hline $\begin{array}{l}\text { Pts system, lichenan-specific IIa } \\
\text { component }\end{array}$ & ADQ90264 & Virulent & \\
\hline ABC transporter ATP-binding-Pr1 & ADQ90875 & Virulent & Garmory et al. 2004 \\
\hline Hypothetical protein & ADQ90910 & Virulent & Twine et al. 2006 \\
\hline $\mathrm{ABC}$ transporter protein & ADQ90806 & Virulent & Garmory et al. 2004 \\
\hline $\begin{array}{l}\text { Sugar ABC transporter } \\
\text { ATP-binding protein }\end{array}$ & ADQ90805 & Virulent & Garmory et al. 2004 \\
\hline MG2+ ion transporter & ADQ90693 & Virulent & $\begin{array}{l}\text { Groisman et al. 2013; Merino } \\
\text { et al. 2001; O'Connor et al. } \\
2009\end{array}$ \\
\hline Ribonuclease III & ADQ90602 & Virulent & $\begin{array}{l}\text { Haddad et al. 2013; Mao et al. } \\
2016\end{array}$ \\
\hline $\begin{array}{l}\text { Ribose-phosphate } \\
\text { pyrophosphokinase }\end{array}$ & ADQ90852 & Virulent & Donini et al. 2017 \\
\hline Putative uncharacterized protein & ADQ90827 & Virulent & \\
\hline Hypothetical protein & ADQ90324 & Virulent & \\
\hline Lipoprotein & ADQ90620 & Virulent & \\
\hline $\begin{array}{l}\text { PTS system galactitol-specific } \\
\text { enzyme IIB component }\end{array}$ & ADQ90760 & Virulent & \\
\hline Enolase & ADQ90480 & Nonvirulent & $\begin{array}{c}\text { Bao et al. 2014; Pancholi 2001; } \\
\text { Schreiner et al. } 2012\end{array}$ \\
\hline Translation elongation factor $\mathrm{Tu}$ & ADQ90729 & Nonvirulent & $\begin{array}{l}\text { Dallo et al. 2002; Jiang et al. } \\
2016\end{array}$ \\
\hline Cation-transporting P-type ATPase & ADQ90498 & Nonvirulent & Novoa-Aponte et al. 2014 \\
\hline $\begin{array}{l}\text { Probable O-sialoglycoprotein } \\
\text { endopeptidase }\end{array}$ & ADQ90833 & Nonvirulent & $\begin{array}{l}\text { Aruni et al. 2011; Davis et al. } \\
2003\end{array}$ \\
\hline Lipoate-protein ligase A & ADQ90531 & Nonvirulent & O'Riordan et al. 2003 \\
\hline Lipoate-protein ligase A & ADQ90484 & Nonvirulent & O'Riordan et al. 2003 \\
\hline Endo-1,4-beta-glucanase & ADQ90389 & Nonvirulent & Robinson et al. 2013 \\
\hline Acetate kinase AckA & ADQ90711 & Nonvirulent & \\
\hline $\begin{array}{l}\text { NADH dependent flavin } \\
\text { oxidoreductase }\end{array}$ & ADQ90532 & Nonvirulent & \\
\hline Glycerol transporter subunit A & ADQ90619 & Nonvirulent & \\
\hline Glycerol kinase & ADQ90587 & Nonvirulent & \\
\hline Triacylglycerol lipase & ADQ90483 & Nonvirulent & \\
\hline $\begin{array}{l}\text { Hypoxanthine } \\
\text { phosphoribosyltransferase }\end{array}$ & ADQ90492 & Nonvirulent & \\
\hline Transport protein sgaT & ADQ90622 & Nonvirulent & \\
\hline CTP synthase & ADQ90509 & Nonvirulent & \\
\hline Thymidine kinase & ADQ90808 & Nonvirulent & \\
\hline Purine-nucleoside phosphorylase & ADQ90309 & Nonvirulent & \\
\hline
\end{tabular}


by the membrane protein P97 [54]. The finding of higher expression levels of P97, protein P97-copy 2, and protein P102-copy 2 in the vaccine strain compared with those of the virulent strain was unexpected, but similar results were also found in the transcriptome comparison between $M$. flocculare and M. hyopneumoniae [10]. A previous study indicated that the cilium binding domain of P97 is found exclusively in the $\mathrm{R} 1$ region, the functional site requiring a minimum of eight tandem repeating units (AAKPV/E) [54]. However, three transversion mutations (E863V) occurred in the tandem repeating units in $\mathrm{P} 97$ of 168L, which might partly affect the adhesion of vaccine strain [5]. P102 accompanies P97 to form a two-gene operon. Both the P97 and P102 genes have several paralogs within the M. hyopneumoniae genome [5]. The sequences of the paralogs are uncompleted. Furthermore, the p97-copy 2 protein of both strains lacks the R1 domain while protein P102-copy 2 was also truncated [5]. Thus, a higher abundance of these proteins might not mean a stronger adhesion ability of the vaccine strain. Adherence to ciliated respiratory epithelium is a multifactorial process that also involves other proteins.

In our proteomic data, we detected several upregulated moonlighting proteins in strain 168 that could be used to invade host cells: elongation factor $\mathrm{Tu}[30,31]$, enolase [29, 32, 34], and endo-1,4-beta-glucanase [33]. Intensive reports have described some bacterial metabolic enzymes not only performing key metabolic functions in the cytosol of bacterial cell but also locating on the bacterial surface without a signal sequence, moonlighting as an adhesion contributor to host cells [55]. These multifunctional proteins located on the mycoplasma surface could adhere to the swine tracheal cilia and bind to host factors plasminogen and fibronectin. Mycoplasma surface-bound plasminogen is converted to plasmin by tissue plasminogen activator. Plasmin cleaves host extracellular matrix proteins and activates matrix metalloproteases, assisting the pathogen to invade host issues and providing amino acids for growth of M. hyopneumoniae [33]. Fibronectin is widespread in the ciliary borders of the bronchioles and could bind to glycosaminoglycans, collagens, DNA, fibrin, and cell surface integrins, etc. These properties of fibronectin make it a physical bridge between pathogens and host cells [56]. Those mycoplasma surface proteins binding to plasminogen and fibronectin have been suggested to be associated with virulence and warrant further investigation.

Significantly expressed protein O-sialoglycoprotein endopeptidase in strain 168 also regulates the invasion of pathogen via degrading sialoglycosylated host-cell proteins and mediating adhesion to host cells $[57,58]$. The traits of these proteins, playing roles in the pathogen-host interactions, affect the pathogenesis of M. hyopneumoniae in part.

Transporters. Transporter proteins play important roles in bacteria, transporting various molecules to support survival and growth in different niches [59]. Cation-transporting P-type ATPase (PacL) is a member of transmembrane Ptype ATPases, which are involved in transportation of ions and phospholipids, using the energy derived from ATP hydrolysis [60-62]. $\mathrm{Mg}^{2+}$ ion transporter (MgtE) is a highly $\mathrm{Mg}^{2+}$-selective channel gated by $\mathrm{Mg}^{2+}$, transporting substrates across the cytoplasmic membrane by utilizing the electrochemical gradient [63]. Both of MgtE and PacL function in maintaining metal homeostasis in pathogen and survival in host, thus considered as virulence determinants in some bacteria [62-65]. Inactivation of ABC transporters often has deleterious effects on the virulence in bacteria, resulting in attenuated phenotypes and decreased adherence to host cells [59]. ABC transporter ATP-binding-Pr1 (Pr1), ABC transporter protein (MHP168_616), and sugar ABC transporter ATP-binding protein (MHP168_615) may be associated with virulence via participating in the regulation of cation homeostasis or adhesive ability. Pts system lichenanspecific IIa component (LicA) and PTS system galactitolspecific enzyme IIB component (MHP168_564) are predicted to be virulent factors on VirulentPred webserver, and their expression levels in strain 168 were upregulated as compared to $168 \mathrm{~L}$, suggesting that these proteins may be suitable targets for antibacterial vaccine and therapies.

Enzymes. Two lipoate-protein ligase A (LplA-1 and LplA) were upregulated in the pathogenic strain 168. LplA ligates exogenous lipoic acid to lipoyl domains of certain metabolic enzymes complexes involved in oxidative metabolism [66]. Previous study showed that growth of LplA1-deficient $L$. monocytogenes was damaged specifically in the host and virulence was $1 / 300$ th as that of wild-type in animals [67]. Possibly, we speculate that LplA could also act as a virulence factor in M. hyopneumoniae.

Enzymes PrsA have been treated as potential targets for therapeutic and vaccine candidates according to previous reports [68]. Cysteinyl-tRNA synthetase is essential for bacteria growth and classified as a "virulent" protein in our predicted results. Increased level of these proteins in virulent strain 168 could support this idea; nonetheless, what kind of part do these proteins play in the pathogenesis and whether they could indeed cause the predicted effects in this strain still needs experimental verification.

Transcriptional Regulator. In strain 168, we found the expression of ribonuclease III (Rnc) was significantly elevated. This ribonuclease is known to be assisting in pathogenesis of other bacteria via regulating the synthesis of virulence factors through RNase III-dependent posttranscriptional manner $[69,70]$; its upexpression in virulent strain made us guess that it might also modulate gene expression of virulent factors in M. hyopneumoniae, therefore contributing to high virulence.

Uncharacterized/Hypothetical Virulence-Related Proteins. According to the previously published genome data, 268 of 695 ( 39\%) M. hyopneumoniae proteins were not assigned functions and annotated as "uncharacterized" or "hypothetical" proteins [15]. In many sequenced bacterial genomes, the uncharacterized/hypothetical proteins account for around $20-40 \%$ of the total genome $[42,71]$, which are important for complementing the genomic and proteomic framework theory. Understanding the functional properties of these proteins will be crucial for a more profound 
TABLE 5: List of predicted functions of differentially expressed uncharacterized/hypothetical proteins.

\begin{tabular}{|c|c|c|c|}
\hline Accession Number & BlastP & pfam & InterPro \\
\hline \multicolumn{4}{|c|}{ proteins which were more abundant in 168} \\
\hline ADQ90691 & $\begin{array}{l}\text { Cof-type HAD-IIB family } \\
\text { hydrolase }\end{array}$ & Hydrolase_3 Domain & None predicted. \\
\hline ADQ90530 & deacetylase SIR2 & No result & $\begin{array}{c}\text { Sirtuin family, catalytic core } \\
\text { domain }\end{array}$ \\
\hline ADQ90824 & $\begin{array}{c}\text { SAM-dependent DNA } \\
\text { methyltransferase }\end{array}$ & N6_Mtase Family & $\begin{array}{l}\text { DNA methylase, } \\
\text { adenine-specific }\end{array}$ \\
\hline ADQ90745 & $\begin{array}{c}\text { Leucine-rich repeat } \\
\text { domain-containing protein }\end{array}$ & LRR_5 Repeat & $\begin{array}{l}\text { BspA type Leucine rich } \\
\text { repeat region }\end{array}$ \\
\hline ADQ90859 & LppA family lipoprotein & No result & None predicted \\
\hline ADQ90910 & $\begin{array}{c}\text { Glycine cleavage system } \\
\text { protein } \mathrm{H} \\
\end{array}$ & GCV_H Domain & None predicted \\
\hline ADQ90827 & $\begin{array}{l}\text { DUF31 domain-containing } \\
\text { protein }\end{array}$ & $\begin{array}{c}\text { DUF31 Domain (Putative } \\
\text { peptidase) }\end{array}$ & Putative peptidase DUF31 \\
\hline ADQ90324 & No result & No result & None predicted \\
\hline \multicolumn{4}{|c|}{ proteins which were more abundant in $168 \mathrm{~L}$} \\
\hline ADQ90289 & $\begin{array}{l}\text { SGNH/GDSL hydrolase } \\
\text { family protein }\end{array}$ & No result & Bromodomain \\
\hline ADQ90727 & $\begin{array}{l}\text { SGNH/GDSL hydrolase } \\
\text { family protein }\end{array}$ & Lipase_GDSL Family & GDSL lipase/esterase \\
\hline ADQ90524 & DEAD/DEAH box helicase & ResIII Family & Helicase/UvrB, N-terminal \\
\hline
\end{tabular}

understanding of the microbes at the molecular machinery level. For pathogens, those proteins with unknown functions probably involve in virulence which help elucidating pathogenesis and are virgin area for developing novel drug/vaccine targets.

In our study, 45 hypothetical proteins and 78 uncharacterized proteins were identified. Among them, 11 uncharacterized/hypothetical proteins displayed differential expression levels, 8 were overrepresented, and 3 were underrepresented in strain 168. It is reasonable for us to suppose that the differentially expressed proteins of unknown function might give a clue for pathogenic mechanisms of $M$. hyopneumoniae or novel drug/vaccine targets. The VirulentPred results showed that all the overrepresented proteins in strain 168 among the differentially expressed uncharacterized/hypothetical proteins are predicted to be associated with virulence. Thus the protein sequences were submitted to BlastP, Pfam, and InterPro web servers for putative function annotation. Table 5 shows the results of the BlastP, Pfam, and InterPro. We also performed the prediction of subcellular localization as a complement to facilitate our knowledge of these uncharacter$\mathrm{ized} /$ hypothetical proteins (Table S4). However, experimental studies should be carried out to assess and confirm their functions in biological processes and pathogenesis.

Proteins ADQ90691, ADQ90727, and ADQ90524 were annotated as hydrolase enzymes. Members of this class are involved in various significant biological processes, including virulence mechanisms $[42,72]$. ADQ90691 was significantly expressed in virulent strain and predicted as a virulence factor, probably playing an important role in the pathogenesis of M. hyopneumoniae. This protein was annotated to be a Cof-like hydrolase, while might function as the phosphatase Cof in E.coli, catalyzing the hydrolysis of 4-amino-2-methyl5-hydroxymethylpyrimidine pyrophosphate to 4-amino-2methyl-5-hydroxymethylpyrimidine phosphate [73].

The hypothetical protein ADQ90530 was categorized as a sirtuin (also known as Sir2), which is responsible for $\mathrm{NAD}^{+}$dependent deacetylation. As the deacetylase of $M$. fermentans is expressed inside mammalian cells, it inhibits cell proliferation but promotes their antioxidation and antistarvation capacities, and alters gene expression, affecting physiological functions and the corresponding signal transduction pathways in host cells [74]. The long-held view is that $M$. hyopneumoniae is an extracellular pathogen, thus it remains unclear whether ADQ90530 in M. hyopneumoniae functions similarly with secreted deacetylase in intracellular pathogen M. fermentans. Elucidating this issue will require further investigation.

Protein ADQ90824 was predicted to be an N-6 adeninespecific DNA methylase, which controls methylation at adenine residues of important biological processes. The methylation process plays an important role in bacterial pathogenesis by regulating the synthesis of virulence factors, and DNA adenine methylases serve as promising antimicrobials and vaccines targets $[42,75]$.

Leucine-rich repeats (LRRs) are found to be present in a number of proteins with diverse functions, including cell-adhesion molecules, virulence factors, and extracellular matrix-binding glycoproteins, and function in signal transduction, cell-adhesion, and protein-protein interactions [76, 
77]. Protein ADQ90745 containing a leucine-rich repeat domain is predicted to be related to virulence, yet more detailed information about its function is unavailable so far.

Uncharacterized protein ADQ90859 belongs to the mycoides cluster lipoprotein, LppA/p72 family; members of this protein family are predicted lipoproteins with a typical prokaryotic signal peptidase II processing and lipid attachment site [78]. Paralogues in other mycoplasmas have been identified as specific antigenic proteins with potential for use in development of diagnostic reagents [78, 79].

Hypothetical protein ADQ90910 was classified as one member (H-protein) of the glycine cleavage system composed of four proteins: the T-, P-, L-, and H-protein. This system catalyzes the reversible reaction: Glycine $+\mathrm{H}_{4}$ folate $+\mathrm{NAD}^{+}<==>5,10$-methylene- $\mathrm{H}_{4}$ folate $+\mathrm{CO}_{2}+\mathrm{NH}_{3}+$ $\mathrm{NADH}+\mathrm{H}^{+}$, and $\mathrm{H}$-protein shuttles some of the intermediate products [80]. H-protein was expressed exclusively in Francisella tularensis isolated from mouse spleens compared with in vitro grown controls, suggesting that H-protein may play an important role in the metabolic fitness of Francisella tularensis [81]. A similar result of predicted H-protein was detected in proteomic analysis of $M$. hyopneumoniae; we assumed hypothetical protein ADQ90910 also play a part in the adaptive response of pathogen to in vivo environment.

The "DUF31" domain that has no known function was found in uncharacterized protein ADQ90827, and none of the domains was predicted in hypothetical protein ADQ90324. The function of them cannot be identified but is predicted to be associated with virulence.

\section{Conclusions}

In conclusion, this survey identified mycoplasmal proteins and unveiled biological processes potentially related to the difference in virulence between the pathogenic and attenuated strains of $M$. hyopneumoniae. The components that play roles in these critical mechanisms are natural targets for specific drugs. These potential virulence factors are usually immunogenic and can be treated as vaccine candidates [82, 83]. Our future experimental work will focus on those proteins to delineate the pathogenic mechanism(s) and identify those which can be targeted for drug design and vaccine development.

\section{Data Availability}

The data used to support the findings of this study are included within the article.

\section{Conflicts of Interest}

The authors declare that there are no conflicts of interest regarding the publication of this paper.

\section{Acknowledgments}

This work was supported by the Key Technology R\&D Programme of China [2015BAD12B02] and the National Natural
Science Foundation of China [31170160 and 31502069]. We would like to thank Dr. Guoqing Shao at Jiangsu Academy of Agricultural Sciences for providing the strains.

\section{Supplementary Materials}

Supplementary 1. Table S1: information of all proteins identified in this study.

Supplementary 2. Table S2: Gene Ontology enrichment analysis for differentially expressed proteins.

Supplementary 3. Table S3: pathway enrichment analysis of the annotated differentially expressed proteins.

Supplementary 4. Table S4: bioinformatic analyses of the differentially expressed uncharacterized/hypothetical proteins.

\section{References}

[1] D. Maes, J. Segales, T. Meyns, M. Sibila, M. Pieters, and F. Haesebrouck, "Control of Mycoplasma hyopneumoniae infections in pigs," Veterinary Microbiology, vol. 126, no. 4, pp. 297-309, 2008.

[2] S. Simionatto, S. B. Marchioro, D. Maes, and O. A. Dellagostin, "Mycoplasma hyopneumoniae: From disease to vaccine development," Veterinary Microbiology, vol. 165, no. 3-4, pp. 234-242, 2013.

[3] F. M. Siqueira, C. E. Thompson, V. G. Virginio et al., "New insights on the biology of swine respiratory tract mycoplasmas from a comparative genome analysis," BMC Genomics, vol. 14, no. 175, pp. 1471-2164, 2013.

[4] A. T. Vasconcelos, H. B. Ferreira, C. V. Bizarro, and etal., "Swine and poultry pathogens: the complete genome sequences of two strains of mycoplasma hyopneumoniae and a strain of mycoplasma synoviae," Journal of Bacteriology, vol. 187, no. 16, pp. 5568-5577, 2005.

[5] W. Liu, S. Xiao, M. Li et al., "Comparative genomic analyses of Mycoplasma hyopneumoniae pathogenic 168 strain and its high-passaged attenuated strain," BMC Genomics, vol. 14, no. 80, pp. 1471-2164, 2013.

[6] M. L. Madsen, D. Nettleton, E. L. Thacker, R. Edwards, and F. C. Minion, "Transcriptional profiling of mycoplasma hyopneumoniae during heat shock using microarrays," Infection and Immunity, vol. 74, no. 1, pp. 160-166, 2005.

[7] M. L. Madsen, D. Nettleton, E. L. Thacker, and F. C. Minion, "Transcriptional profiling of Mycoplasma hyopneumoniae during iron depletion using microarrays," Microbiology, vol. 152, no. 4, pp. 937-944, 2006.

[8] M. L. Madsen, S. Puttamreddy, E. L. Thacker, M. D. Carruthers, and F. C. Minion, "Transcriptome changes in mycoplasma hyopneumoniae during infection," Infection and Immunity, vol. 76, no. 2, pp. 658-663, 2008.

[9] M. J. Oneal, E. R. Schafer, M. L. Madsen, and F. C. Minion, "Global transcriptional analysis of Mycoplasma hyopneumoniae following exposure to norepinephrine," Microbiology, vol. 154, no. 9, pp. 2581-2588, 2008.

[10] F. M. Siqueira, A. L. Gerber, R. L. M. Guedes et al., "Unravelling the transcriptome profile of the swine respiratory tract mycoplasmas," PLoS ONE, vol. 9, no. 10, 2014.

[11] Y. Li, Y. Ho, S. Chen, T. Chiou, Z. Li, and D. Shiuan, "Proteomic comparative analysis of pathogenic strain 232 and avirulent strain J of Mycoplasma hyopneumoniae," Biochemistry (Moscow), vol. 74, no. 2, pp. 215-220, 2009. 
[12] P. M. Pinto, C. S. Klein, A. Zaha, and H. B. Ferreira, "Comparative proteomic analysis of pathogenic and non-pathogenic strains from the swine pathogen Mycoplasma hyopneumoniae," Proteome Science, vol. 7, no. 45, pp. 1477-5956, 2009.

[13] Y. Yu, M. Liu, L. Hua et al., "Fructose-1,6-bisphosphate aldolase encoded by a core gene of Mycoplasma hyopneumoniae contributes to host cell adhesion," Veterinary Research, vol. 49, no. 1, pp. 018-0610, 2018.

[14] J. A. Paes, L. D. Machado, F. M. dos Anjos Leal et al., “ Comparative proteomics of two Mycoplasma hyopneumoniae strains and Mycoplasma flocculare identified potential porcine enzootic pneumonia determinants ," Virulence, vol. 9, no. 1, pp. 1230-1246, 2018.

[15] W. Liu, Z. Feng, L. Fang et al., "Complete genome sequence of mycoplasma hyopneumoniae strain 168," Journal of Bacteriology, vol. 193, no. 4, pp. 1016-1017, 2011.

[16] Q. Xiong, Y. Wei, H. Xie et al., "Effect of different adjuvant formulations on the immunogenicity and protective effect of a live Mycoplasma hyopneumoniae vaccine after intramuscular inoculation," Vaccine, vol. 32, no. 27, pp. 3445-3451, 2014.

[17] D. Calus, D. Maes, K. Vranckx, I. Villareal, F. Pasmans, and F. Haesebrouck, "Validation of ATP luminometry for rapid and accurate titration of Mycoplasma hyopneumoniae in Friis medium and a comparison with the color changing units assay," Journal of Microbiological Methods, vol. 83, no. 3, pp. 335-340, 2010.

[18] M. R. Wilkins, E. Gasteiger, A. Bairoch et al., "Protein identification and analysis tools in the ExPASy server," Methods in Molecular Biology, vol. 112, pp. 531-552, 1999.

[19] F. S. Berven, O. A. Karlsen, A. H. Straume et al., "Analysing the outer membrane subproteome of Methylococcus capsulatus (Bath) using proteomics and novel biocomputing tools," Archives of Microbiology, vol. 184, no. 6, pp. 362-377, 2006.

[20] A. S. Juncker, H. Willenbrock, G. von Heijne, S. Brunak, H. Nielsen, and A. Krogh, "Prediction of lipoprotein signal peptides in Gram-negative bacteria," Protein Science, vol. 12, no. 8, pp. 1652-1662, 2003.

[21] N. Y. Yu, J. R. Wagner, M. R. Laird et al., "PSORTb 3.0: improved protein subcellular localization prediction with refined localization subcategories and predictive capabilities for all prokaryotes," Bioinformatics, vol. 26, no. 13, pp. 1608-1615, 2010.

[22] C. S. Yu, C. J. Lin, and J. K. Hwang, "Predicting subcellular localization of proteins for Gram-negative bacteria by support vector machines based on n-peptide compositions," Protein Science, vol. 13, no. 5, pp. 1402-1406, 2004.

[23] A. Krogh, B. Larsson, G. Von Heijne, and E. L. L. Sonnhammer, "Predicting transmembrane protein topology with a hidden Markov model: application to complete genomes," Journal of Molecular Biology, vol. 305, no. 3, pp. 567-580, 2001.

[24] T. N. Petersen, S. Brunak, G. Von Heijne, and H. Nielsen, "SignalP 4.0: discriminating signal peptides from transmembrane regions," Nature Methods, vol. 8, no. 10, pp. 785-786, 2011.

[25] J. D. Bendtsen, L. Kiemer, A. Fausbøll, and S. Brunak, "Nonclassical protein secretion in bacteria," BMC Microbiology, vol. 5, no. 58, pp. 1471-2180, 2005.

[26] S. El-Gebali, J. Mistry, A. Bateman et al., "The Pfam protein families database in 2019," Nucleic Acids Research, vol. 47, no. D1, pp. D427-D432, 2019.

[27] A. L. Mitchell, T. K. Attwood, P. C. Babbitt et al., "InterPro in 2019: improving coverage, classification and access to protein sequence annotations," Nucleic Acids Research, vol. 47, no. D1, pp. D351-D360, 2019.
[28] S. Saha and G. P. S. Raghava, "VICMpred: an SVM-based method for the prediction of functional proteins of gramnegative bacteria using amino acid patterns and composition," Genomics, Proteomics \& Bioinformatics, vol. 4, no. 1, pp. 42-47, 2006.

[29] S. Bao, X. Guo, S. Yu et al., "Mycoplasma synoviaeenolase is a plasminogen/fibronectin binding protein," BMC Veterinary Research, vol. 10, no. 223, pp. 014-0223, 2014.

[30] S. F. Dallo, T. R. Kannan, M. W. Blaylock, and J. B. Baseman, "Elongation factor $\mathrm{Tu}$ and $\mathrm{E} 1 \beta$ subunit of pyruvate dehydrogenase complex act as fibronectin binding proteins in Mycoplasma pneumoniae," Molecular Microbiology, vol. 46, no. 4, pp. 1041-1051, 2002.

[31] F. Jiang, J. He, N. Navarro-Alvarez et al., "Elongation factor Tu and heat shock protein 70 are membrane-associated proteins from Mycoplasma ovipneumoniae capable of inducing strong immune response in mice," Plos One, vol. 11, no. 8, 2016.

[32] V. Pancholi, "Multifunctional alpha-enolase: its role in diseases," Cellular and Molecular Life Sciences, vol. 58, no. 7, pp. 902-920, 2001.

[33] M. W. Robinson, K. A. Buchtmann, C. Jenkins et al., "MHJ0125 is an M42 glutamyl aminopeptidase that moonlights as a multifunctional adhesin on the surface of Mycoplasma hyopneumoniae," Open Biology, vol. 3, no. 4, Article ID 130017, 2013.

[34] S. A. Schreiner, A. Sokoli, K. M. Felder et al., "The surfacelocalised $\alpha$-enolase of Mycoplasma suis is an adhesion protein," Veterinary Microbiology, vol. 156, no. 1-2, pp. 88-95, 2012.

[35] M. G. Ferrarini, F. M. Siqueira, S. G. Mucha et al., "Insights on the virulence of swine respiratory tract mycoplasmas through genome-scale metabolic modeling," BMC Genomics, vol. 17, no. 353, pp. 016-264, 2016.

[36] M. G. Ferrarini, S. G. Mucha, D. Parrot et al., “ Hydrogen peroxide production and myo-inositol metabolism as important traits for virulence of Mycoplasma hyopneumoniae," Molecular Microbiology, vol. 108, no. 6, pp. 683-696, 2018.

[37] T. B. Reynolds, "Strategies for acquiring the phospholipid metabolite inositol in pathogenic bacteria, fungi and protozoa: making it and taking it," Microbiology, vol. 155, no. 5, pp. 13861396, 2009.

[38] R. Veldhuizen, K. Nag, S. Orgeig, and F. Possmayer, "The role of lipids in pulmonary surfactant," Biochimica et Biophysica Acta, vol. 19, pp. 2-3, 1998.

[39] C. V. Bizarro and D. C. Schuck, "Purine and pyrimidine nucleotide metabolism in Mollicutes," Genetics and Molecular Biology, vol. 30, no. 1, pp. 1271-1295, 2007.

[40] B. Hove-Jensen, "Mutation in the phosphoribosylpyrophosphate synthetase gene (prs) that results in simultaneous requirements for purine and pyrimidine nucleosides, nicotinamide nucleotide, histidine, and tryptophan in Escherichia coli.," Journal of Bacteriology, vol. 170, no. 3, pp. 1148-1152, 1988.

[41] A. Kuehne, H. Emmert, J. Soehle et al., "Acute activation of oxidative pentose phosphate pathway as first-line response to oxidative stress in human skin cells," Molecular Cell, vol. 59, no. 3, pp. 359-371, 2015.

[42] M. Shahbaaz, K. Bisetty, F. Ahmad, and M. I. Hassan, "In silico approaches for the identification of virulence candidates amongst hypothetical proteins of Mycoplasma pneumoniae 309," Computational Biology and Chemistry, vol. 59, pp. 67-80, 2015.

[43] K. C. S. Bouh, F. Shareck, and S. Dea, "Monoclonal antibodies to Escherichia coli-expressed P46 and P65 membranous proteins 
for specific immunodetection of Mycoplasma hyopneumoniae in lungs of infected pigs," Clinical and Diagnostic Laboratory Immunology, vol. 10, no. 3, pp. 459-468, 2003.

[44] G. Browning, M. Marenda, A. Noormohammadi, and P. Markham, "The central role of lipoproteins in the pathogenesis of mycoplasmoses," Veterinary Microbiology, vol. 153, no. 1-2, pp. 44-50, 2011.

[45] S. Futo, Y. Seto, M. Okada et al., "Recombinant 46-kilodalton surface antigen (P46) of Mycoplasma hyopneumoniae expressed in Escherichia coli can be used for early specific diagnosis of mycoplasmal pneumonia of swine by enzymelinked immunosorbent assay," Journal of Clinical Microbiology, vol. 33, no. 3, pp. 680-683, 1995.

[46] J. A. Schmidt, G. F. Browning, and P. F. Markham, "Mycoplasma hyopneumoniae p65 surface lipoprotein is a lipolytic enzyme with a preference for shorter-chain fatty acids," Journal of Bacteriology, vol. 186, no. 17, pp. 5790-5798, 2004.

[47] J. A. Schmidt, G. F. Browning, and P. F. Markham, "Mycoplasma hyopneumoniae mhp379 Is a Ca2+-dependent, sugarnonspecific exonuclease exposed on the cell surface," Journal of Bacteriology, vol. 189, no. 9, pp. 3414-3424, 2007.

[48] T. Stakenborg, J. Vicca, D. Maes et al., "Comparison of molecular techniques for the typing of Mycoplasma hyopneumoniae isolates," Journal of Microbiological Methods, vol. 66, no. 2, pp. 263-275, 2006.

[49] V. G. Virginio, T. Gonchoroski, J. A. Paes, D. C. Schuck, A. Zaha, and H. B. Ferreira, "Immune responses elicited by Mycoplasma hyopneumoniae recombinant antigens and DNA constructs with potential for use in vaccination against porcine enzootic pneumonia," Vaccine, vol. 32, no. 44, pp. 5832-5838, 2014.

[50] J. Meens, M. Selke, and G. Gerlach, "Identification and immunological characterization of conserved Mycoplasma hyopneumoniae lipoproteins Mhp378 and Mhp651," Veterinary Microbiology, vol. 116, no. 1-3, pp. 85-95, 2006.

[51] W. Liu, D. Zhou, F. Yuan et al., "Surface proteins mhp390 (P68) contributes to cilium adherence and mediates inflammation and apoptosis in Mycoplasma hyopneumoniae," Microbial Pathogenesis, vol. 126, pp. 92-100, 2019.

[52] F. C. Minion, E. J. Lefkowitz, M. L. Madsen, B. J. Cleary, S. M. Swartzell, and G. G. Mahairas, "The genome sequence of mycoplasma hyopneumoniae strain 232, the agent of swine mycoplasmosis," Journal of Bacteriology, vol. 186, no. 21, pp. 7123-7133, 2004.

[53] J. L. Tacchi, B. B. A. Raymond, P. A. Haynes et al., "Posttranslational processing targets functionally diverse proteins in Mycoplasma hyopneumoniae," Open Biology, vol. 6, no. 2, Article ID 150210, 2016.

[54] F. C. Minion, C. Adams, and T. Hsu, "R1 region of P97 mediates adherence of mycoplasma hyopneumoniae to swine cilia," Infection and Immunity, vol. 68, no. 5, pp. 3056-3060, 2000.

[55] B. Henderson and A. Martin, "Bacterial virulence in the moonlight: multitasking bacterial moonlighting proteins are virulence determinants in infectious disease," Infection and Immunity, vol. 79, no. 9, pp. 3476-3491, 2011.

[56] B. Henderson, S. Nair, J. Pallas, and M. A. Williams, "Fibronectin: a multidomain host adhesin targeted by bacterial fibronectin-binding proteins," FEMS Microbiology Reviews, vol. 35, no. 1, pp. 147-200, 2011.
[57] W. Aruni, E. Vanterpool, D. Osbourne et al., "Sialidase and Sialoglycoproteases Can Modulate Virulence in Porphyromonas gingivalis," Infection and Immunity, vol. 79, no. 7, pp. 2779-2791, 2011.

[58] R. E. Davis, R. Jomantiene, Y. Zhao, and E. L. Dally, "Folate biosynthesis pseudogenes, PsifolP and PsifolK, and an $\mathrm{O}$ sialoglycoprotein endopeptidase gene homolog in the phytoplasma genome," DNA and Cell Biology, vol. 22, no. 11, pp. 697706, 2003.

[59] H. S. Garmory and R. W. Titball, "ATP-binding cassette transporters are targets for the development of antibacterial vaccines and therapies," Infection and Immunity, vol. 72, no. 12, pp. 67576763, 2004.

[60] T. Berkelman, P. Garret-Engele, and N. E. Hoffman, "The pacL gene of Synechococcus sp. strain PCC 7942 encodes a $\mathrm{Ca}(2+)$ transporting ATPase.," Journal of Bacteriology, vol. 176, no. 14, pp. 4430-4436, 1994.

[61] K. L. Hein, P. Nissen, and J. P. Morth, "Purification, crystallization and preliminary crystallographic studies of a PacL homologue from Listeria monocytogenes," Acta Crystallographica Section F: Structural Biology Communications, vol. 68, no. 4, pp. 424-427, 2012.

[62] L. Novoa-Aponte and C. Y. Soto Ospina, "Mycobacterium tuberculosis P-type ATPases: possible targets for drug or vaccine development," BioMed Research International, vol. 2014, Article ID 296986, 9 pages, 2014.

[63] E. A. Groisman, K. Hollands, M. A. Kriner, E. Lee, S. Park, and M. H. Pontes, "Bacterial $\mathrm{Mg}^{2+}$ homeostasis, transport, and virulence," Annual Review of Genetics, vol. 47, no. 1, pp. 625-646, 2013.

[64] K. O’Connor, S. A. Fletcher, and L. N. Csonka, "Increased expression of $\mathrm{Mg} 2+$ transport proteins enhances the survival of Salmonella enterica at high temperature," Proceedings of the National Acadamy of Sciences of the United States of America, vol. 106, no. 41, pp. 17522-17527, 2009.

[65] S. Merino, R. Gavin, M. Altarriba et al., "The MgtE Mg2+ transport protein is involved in Aeromonas hydrophila adherence," FEMS Microbiology Letters, vol. 198, no. 2, pp. 189-195.

[66] K. M. Keeney, J. A. Stuckey, and M. X. O'Riordan, "LplA1dependent utilization of host lipoyl peptides enables Listeria cytosolic growth and virulence," Molecular Microbiology, vol. 66 , no. 3, pp. 758-770, 2007.

[67] M. O’Riordan, M. A. Moors, and D. A. Portnoy, “Listeria intracellular growth and virulence require host-derived lipoic acid," Science, vol. 302, no. 5644, pp. 462-464, 2003.

[68] S. Donini, S. Garavaglia, D. M. Ferraris et al., "Biochemical and structural investigations on phosphoribosylpyrophosphate synthetase from mycobacterium smegmatis," PLoS ONE, vol. 12, no. $4,2017$.

[69] N. Haddad, M. Saramago, R. G. Matos, H. Prevost, and C. M. Arraiano, "Characterization of the biochemical properties of Campylobacter jejuni RNase III," Bioscience Reports, vol. 33, no. 6, 2013.

[70] M.-Y. Mao, Y.-M. Yang, K.-Z. Li et al., “The rnc gene promotes exopolysaccharide synthesis and represses the vicRKX gene expressions via microRNA-size small RNAs in Streptococcus mutans," Frontiers in Microbiology, vol. 7, no. 687, 2016.

[71] G. Singh, D. Sharma, V. Singh et al., "In silico functional elucidation of uncharacterized proteins of Chlamydia abortus strain LLG," Future Science OA, vol. 3, no. 1, pp. 2016-2066, 2017.

[72] N. A. Okan, S. Chalabaev, T.-H. Kim, A. Fink, R. A. Ross, and D. L. Kasper, "Kdo hydrolase is required for francisella tularensis 
virulence and evasion of TLR2-mediated innate immunity," mBio, vol. 4, no. 1, Article ID 00638-12, 2013.

[73] B. G. Lawhorn, S. Y. Gerdes, and T. P. Begley, "A genetic screen for the identification of thiamin metabolic genes," The Journal of Biological Chemistry, vol. 279, no. 42, pp. 43555-43559, 2004.

[74] Q. Cheng, L. Wu, R. Tu et al., "Mycoplasma fermentans deacetylase promotes mammalian cell stress tolerance," Microbiological Research, vol. 201, pp. 1-11, 2017.

[75] D. M. Heithoff, R. L. Sinsheimer, D. A. Low, and M. J. Mahan, "An essential role for DNA adenine methylation in bacterial virulence," Science, vol. 284, no. 5416, pp. 967-970.

[76] B. Kobe and A. V. Kajava, “The leucine-rich repeat as a protein recognition motif," Current Opinion in Structural Biology, vol. 11, no. 6, pp. 725-732, 2001.

[77] N. J. Gay, L. C. Packman, M. A. Weldon, and J. C. J. Barna, "A leucine-rich repeat peptide derived from the Drosophila Toll receptor forms extended filaments with a $\beta$-sheet structure," FEBS Letters, vol. 291, no. 1, pp. 87-91, 1991.

[78] X. Cheng, J. Nicolet, R. Miserez et al., "Characterization of the gene for an immunodominant $72 \mathrm{kDa}$ lipoprotein of Mycoplasma mycoides subsp. mycoides small colony type," Microbiology, vol. 142, no. 12, pp. 3515-3524, 1996.

[79] M. Monnerat, F. Thiaucourt, J. Nicolet, and J. Frey, "Comparative analysis of the lppA locus in Mycoplasma capricolum subsp. capricolum and Mycoplasma capricolum subsp. capripneumoniae," Veterinary Microbiology, vol. 69, no. 3, pp. 157-172, 1999.

[80] G. Kikuchi, Y. Motokawa, T. Yoshida et al., "Glycine cleavage system, reaction mechanism, physiological significance, and hyperglycinemia," Proceedings of the Japan Academy, Series B, vol. 84, no. 7, pp. 246-263, 2008.

[81] S. M. Twine, N. C. Mykytczuk, M. D. Petit et al., "In vivo proteomic analysis of the intracellular bacterial pathogen, Francisella tularensis, isolated from mouse spleen," Biochemical and Biophysical Research Communications, vol. 345, no. 4, pp. 1621-1633, 2006.

[82] E. Allan and B. W. Wren, "Genes to genetic immunization: identification of bacterial vaccine candidates," Methods, vol. 31, no. 3, pp. 193-198, 2003.

[83] H. B. Ferreira and L. A. Castro, "A preliminary survey of M. hyopneumoniae virulence factors based on comparative genomic analysis," Genetics and Molecular Biology, vol. 30, no. 1, pp. 245-255, 2007. 


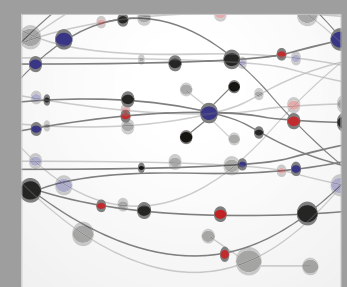

The Scientific World Journal
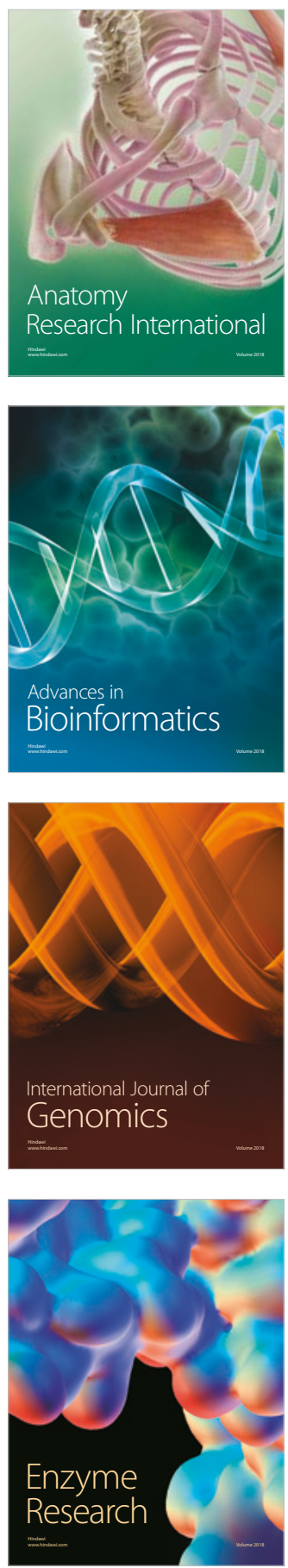
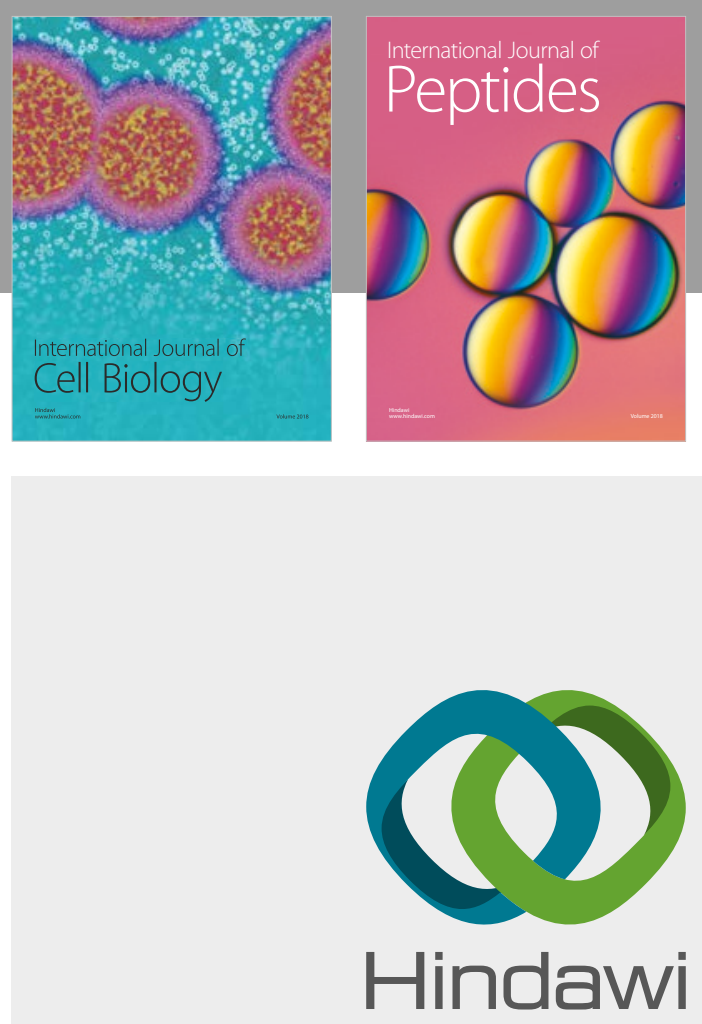

Submit your manuscripts at

www.hindawi.com
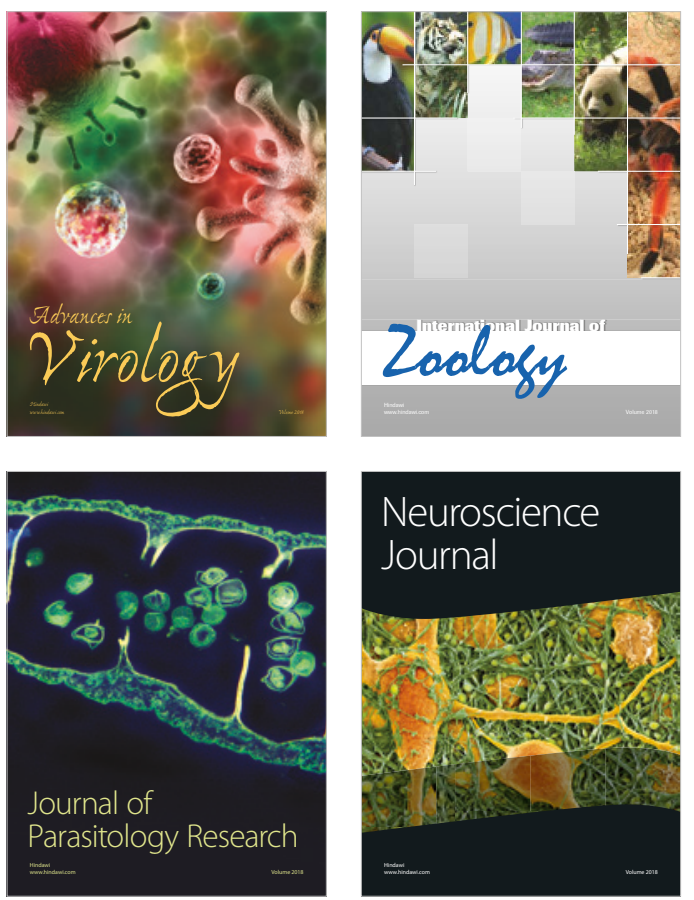
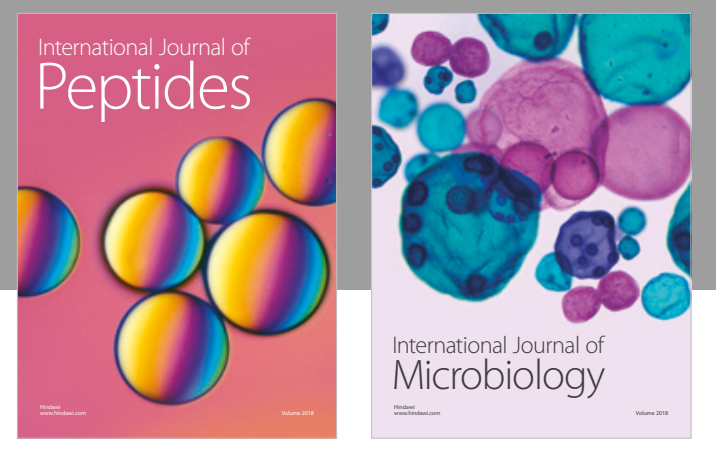

nternational Journal of Microbiology
Journal of
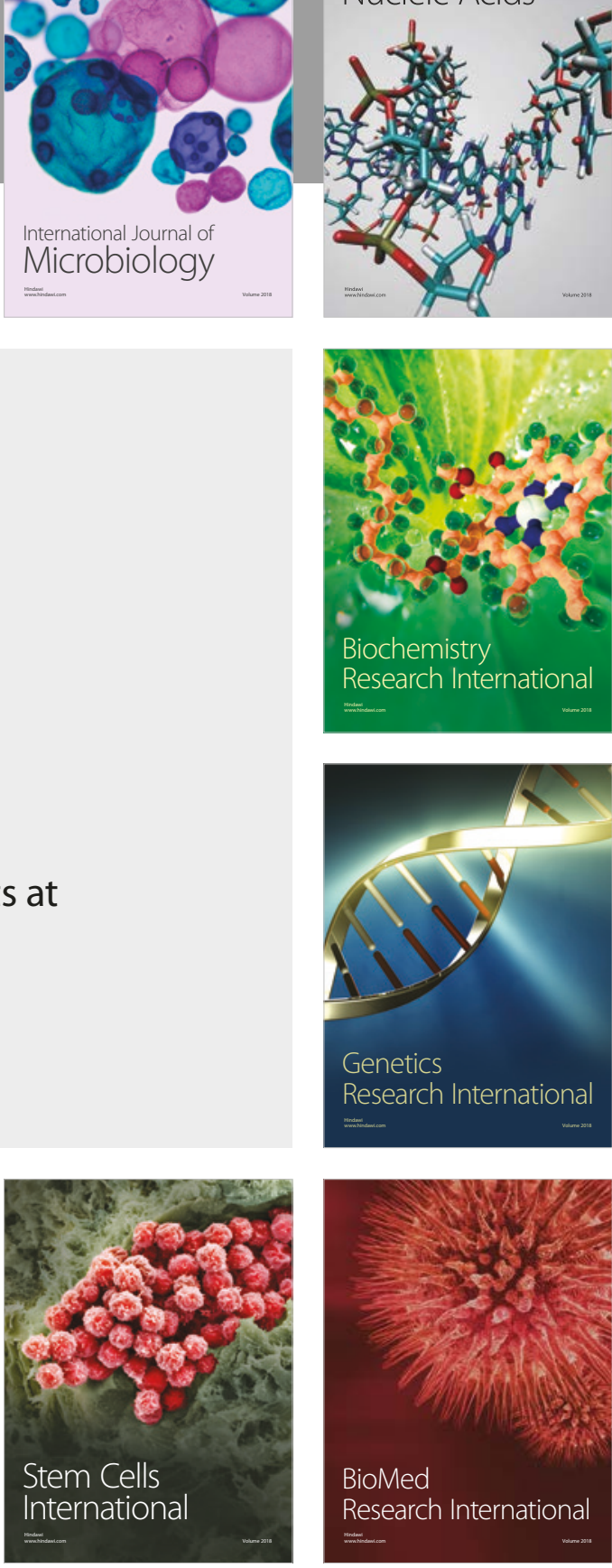
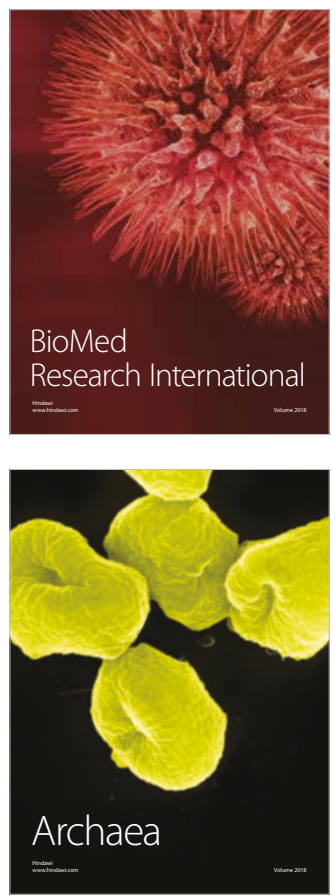